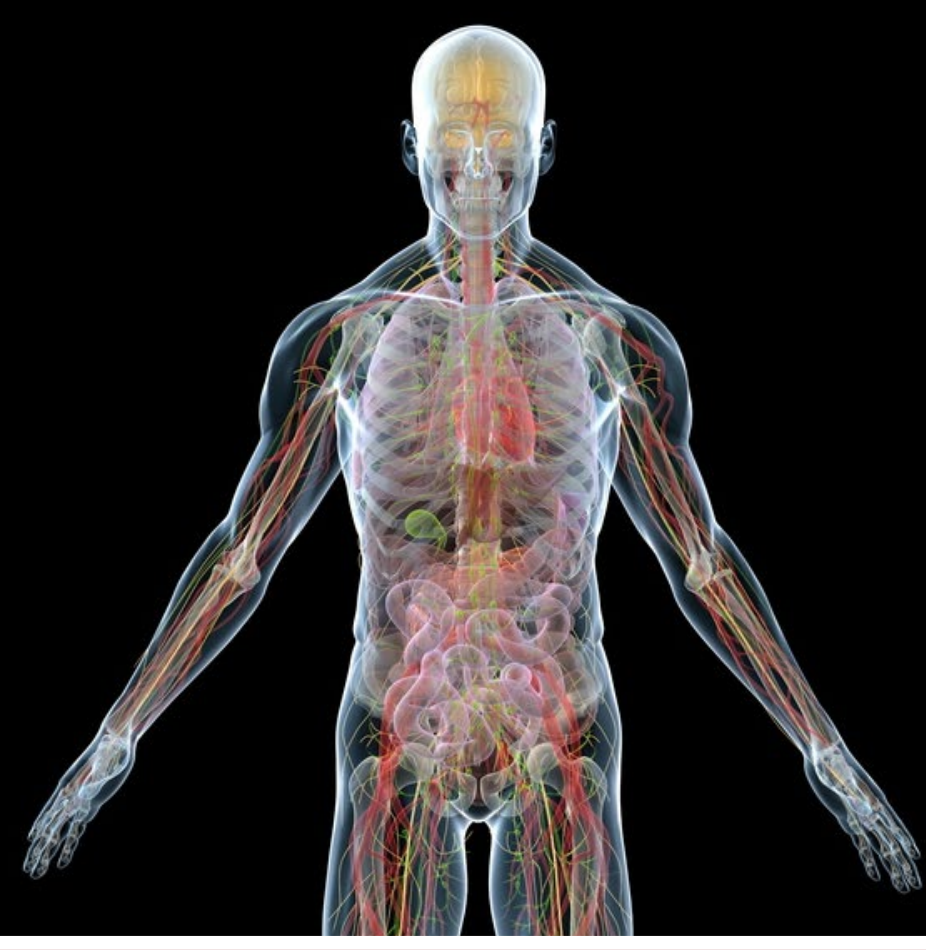

Human enhancement and the future of work

Report from a joint workshop hosted by the Academy of Medical Sciences, the British Academy, the Royal Academy of Engineering and the Royal Society. 


\section{Academy of Medical Sciences}

The independent Academy of Medical Sciences promotes advances in medical science and campaigns to ensure these are translated into benefits for patients. The Academy's Fellows are the United Kingdom's leading medical scientists from hospitals, academia, industry and the public service.

\section{British Academy}

The British Academy, established by Royal Charter in 1902, champions and supports the humanities and social sciences. It aims to inspire, recognise and support excellence in the humanities and social sciences, throughout the UK and internationally, and to champion their role and value. The British Academy is an independent, self-governing fellowship of scholars elected for their distinction and achievement.

\section{Royal Academy of Engineering}

As the UK's national academy for engineering, we bring together the most successful and talented engineers from across the engineering sectors for a shared purpose: to advance and promote excellence in engineering. We provide analysis and policy support to promote the UK's role as a great place from which to do business. We take a lead on engineering education and we invest in the UK's world class research base to underpin innovation. We work to improve public awareness and understanding of engineering. We are a national academy with a global outlook and use our international partnerships to ensure that the UK benefits from international networks, expertise and investment.

\section{The Royal Society}

The Royal Society is a self-governing Fellowship of many of the world's most distinguished scientists drawn from all areas of science, engineering, and medicine. The Society's fundamental purpose, as it has been since its foundation in 1660, is to recognise, promote, and support excellence in science and to encourage the development and use of science for the benefit of humanity. For more information visit royalsociety.org

ISBN No: 978-1-903401-35-4 


\section{The Academy of Medical Sciences

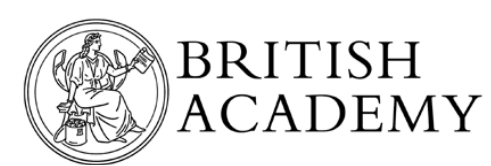 \\ ROYAL

\section{Human enhancement and the future of work}

Report from a joint workshop hosted by the Academy of Medical Sciences, the British Academy, the Royal Academy of Engineering and the Royal Society. 


\section{Acknowledgements and disclaimer}

Cognisant of the lack of debate about the potential impact of human enhancement in the workplace, the Academy of Medical Sciences, British Academy, Royal Academy of Engineering and Royal Society came together to consider the implications of human enhancement technologies for the future of work. The Academies convened a small policy-focused workshop on 7 March 2012, which brought together policy-makers with leading experts from across engineering, science, social science, the humanities and industry. The Academies are very grateful to the steering committee, chaired by Professor Genevra Richardson CBE FBA, which has overseen this project. This is the first time that these four academies have combined their expertise to consider the policy implications of developments in a diverse range of research fields.

This report captures the themes and questions that emerged from the workshop and does not necessarily represent the views of the four host academies.

All web references were accessed in October 2012.

(C) The Academy of Medical Sciences 


\section{Contents}

$\begin{array}{lr}\text { Summary } & 5\end{array}$

$\begin{array}{lr}1 \text { Introduction } & 9\end{array}$

2 Cognitive enhancement $\quad 13$

3 Physical enhancement 23

4 Commercialisation opportunities and challenges

5 Potential implications for the future of work

6 Policy and regulatory implications $\quad 49$

$\begin{array}{ll}7 \text { Conclusion } & 53\end{array}$

$\begin{array}{ll}\text { Annex I Workshop programme } & 55\end{array}$

$\begin{array}{ll}\text { Annex II Steering committee membership } & 57\end{array}$

Annex III Workshop participants

$\begin{array}{ll}\text { Glossary } & 61\end{array}$ 


\section{Summary}

Over the next few decades, the nature of paid work is likely to change significantly owing, for example, to the ageing workforce and changing working practices. Although human enhancement technologies might aid society in dealing with this transition, their use at work is likely to have implications that require careful consideration, particularly by policy-makers, employers, employees, researchers and wider society. Any such use would have impacts across the population and on individuals both employed and not employed. Human enhancement has been widely debated and discussions usually focus on the desire to improve performance. Although the context of work is clearly a primary application of these technologies, debate around human enhancement has not specifically considered the context of work.

Cognisant of the lack of debate about the potential impact of human enhancement in the workplace, the Academy of Medical Sciences, British Academy, Royal Academy of Engineering and Royal Society jointly hosted a workshop to consider this topic on 7 March 2012. Human enhancement refers to endeavours that are designed or used to restore or improve human performance, thus overcoming the current limits of one's human body (see Box 1). This workshop was concerned with novel technologies that have the potential to extend an individual's capacities beyond their current limits. This interdisciplinary workshop brought together policy-makers with leading experts from across engineering, science, social science, the humanities and industry. The workshop provided insights into enhancements that might arise from advances in science and engineering that are likely to impact on the future of work, and it considered the associated opportunities and challenges for all stakeholders and for policy in particular. To capture the range of future technologies most accurately, the workshop primarily focused on technologies likely to impact on work in the next decade.
A fundamental aspect of this discussion relates to the ultimate objective of enhancement. Potential outcomes exist along a spectrum, from increasing participation in work among those who might otherwise be disadvantaged or excluded, to improving the performance and efficiency of all employees beyond the current limits of human capacity. Any effective regulatory framework would need to reflect these different objectives. Attention also needs to be given to the risk that people will be put under pressure to enhance their ability to tolerate demanding work such as shift working; this risk will be greatest for those with the weakest labour market conditions. Attendees were keen to stress that these technologies are not a substitute for improving conditions of work.

This report outlines selected developments from across science and engineering that could enable both cognitive and physical enhancement, although it is not exhaustive. It summarises the themes and issues raised during the workshop. Given that there is currently little debate about the use of enhancements at work or an academic research base to draw upon, the report aims to highlight possible implications of such use, which are likely to be complex, and to identify potential areas for debate. Key messages identified by workshop participants include the following:

\section{- Enhancement technologies could} change how people work. Work

will evolve over the next decade, with enhancement technologies potentially making a significant contribution. Widespread use of enhancements might influence an individual's ability to learn or perform tasks and perhaps even to enter a profession; influence motivation; enable people to work in more extreme conditions or into old age, reduce work-related illness; or facilitate earlier return to work after illness. 
- Implications will be complex and there will be multiple political and social

tensions. There are many instances where the possible implications of enhancement at work will be complex and potentially divisive. Enhancement could benefit employee efficiency and even work-life balance, but there is a risk that it will be seen as a solution to increasingly challenging working conditions, which could have implications for employee wellbeing. Enabling an ageing workforce to delay retirement would have implications for youth employment.

- The distinction between enhancement and restoration is difficult. The workshop aimed to consider enhancement technologies as both restorative and taking individuals 'beyond the norm'. Although 'norm' is a challenging concept, this distinction may be integral to considerations of the acceptability of new technologies, and thus to regulatory decisions. The use of restorative technologies might facilitate a diminishing of the line between the disabled and the non-disabled with both negative and positive consequences.

- The use of enhancements will vary with context. Usefulness will vary between individuals and occupations. In addition, work will evolve over the next decade and beyond, and this will influence the role that enhancements play in the future. To maximise any benefit from enhancement technologies, we must understand the complexities of these context-specific outcomes and involve individuals in the design and integration of technologies, and in the design of any regulatory frameworks.

- It is helpful to identify whether issues are unique to human enhancement.

If the issues raised are familiar, we must identify relevant contexts from which we can learn. In cases where unprecedented concerns exist, careful consideration and wider dialogue will be important.
- A range of policy questions will need to be addressed. Although enhancement technologies might bring opportunities, they also raise several health, safety, ethical, social and political challenges, which warrant proactive discussion. Very different regulatory regimes are currently applied: for example, digital services and devices (with significant cognitive enhancing effects) attract less, if any, regulatory oversight than pharmacological interventions. This raises significant questions, such as whether any form of self-regulation would be appropriate and whether there are circumstances where enhancements should be encouraged or even mandatory, particularly where work involves responsibility for the safety of others (e.g. bus drivers or airline pilots).

- Empirical data are needed to guide policy. 'Known unknowns' need to be addressed by studies on short- and longterm impacts (both positive and negative) of enhancements on individuals with detailed consideration of social and ethical impacts using deliberative dialogue with users, potential users and wider society and the development of a market map to guide commercialisation. Continuous monitoring to inform the re-assessment of any policy or regulatory decisions is vital but will also require these underpinning data.

\section{- Policy must be informed by open} dialogue. We must engage publics in open dialogue about the prospects of enhancement technologies and how they might be used at work, particularly given that use at work would affect the entire population, both those employed and not employed. Sources of input should include users of enhancements, older populations, trade unions, as well as those with expertise with novel innovations and technologies. Policy-makers and publics must be equipped to recognise circumstances in which, for example, claims around the benefits of new technologies are inflated. 
- The cost of technologies will be

crucial. Cost and cost-benefit analysis are clearly key factors in determining who funds provision, which in turn will impact on equality and justice. Cost also drives investment decisions and will therefore be important in determining commercialisation opportunities.

- Development of enhancement technologies might offer economic opportunities. There may be an opportunity to create a new human enhancement industry in the UK; bringing together the UK's leading innovators in the fields of physics, biology, chemistry, engineering and design in addition to the application of enhancements to employees working within current UK industries to increase the competitiveness of the workforce.

\section{- The international aspect of} enhancement is inescapable. Regulation will need to be sensitive to technological development and international competition, both in terms of developing technologies and using them to improve performance.
- The availability of enhancements will be influential. Although the cost of some enhancement technologies will render them inaccessible to all but the very few, raising questions of equality and justice, other technologies such as pharmacological cognition enhancers, are already readily available through the internet-posing imminent challenges for effective regulation. Likewise, digital devices and services with the potential to influence cognition are emerging continuously with little research into the risks and benefits.

\section{- Interdisciplinary approaches} will be key to moving forward. In developing new technologies, whether they are cognitive training or bionic limbs, interdisciplinary approaches will facilitate better understanding of how best to proceed. This also applies to implementation: if any enhancement is seen as valuable, scientists need to work together with social scientists, philosophers, ethicists, policy-makers and the public to discuss the ethical and moral consequences of enhancement, and thus to harness maximum benefit with minimal harm.

\section{Box 1 What is meant by human enhancement?}

The term 'human enhancement' encompasses a range of approaches that may be used to improve aspects of human function (e.g. memory, hearing, mobility). This may either be for the purpose of restoring an impaired function to previous or average levels, or to raise function to a level considered to be 'beyond the norm' for humans.

This is often achieved through technological means, with examples including the following:

- The use of cognitive enhancing drugs to improve memory and concentration.

- The use of hearing aids and retinal implants to improve sensory perception.

- The use of bionic limbs to restore mobility.

These examples demonstrate that new enhancement techniques arise from a range of disciplines including biotechnology, engineering, neuroscience and computing. The social, political, ethical, economic and regulatory issues raised by their use further highlight the interdisciplinary nature of this topic. 


\section{Introduction}

Human enhancement refers to endeavours that are designed or used to restore or improve human performance, thus overcoming the current limits of one's human body. Advances in fields such as biotechnology, engineering, neuroscience and computing bring the potential for novel enhancement technologies that could have significant implications for individuals and society. The development and use of these enhancements raise a range of scientific, engineering, social, political, ethical, economic and regulatory issues. In using the term 'enhancement' throughout this report we do not intend to imply that a consensus exists on how and whether humans might be 'improved' or that there will only be positive outcomes to any enhancement. Alternative terms such as 'modulation' have been suggested and there is merit in considering such alternatives as debate about the application of these technologies progresses.

The UK will see significant changes to its demographics over the next decade and beyond. For example, there are currently 10 million people in the UK who are over 65 years old. It is estimated that this figure will rise by approximately 5.5 million over the next 20 years and almost double to around 19 million by the year 2050. ${ }^{1}$ Demographic shifts will be accompanied by changes to the nature of work, and both of these transitions will influence the context in which enhancements might be used. The workshop focused primarily on paid work, rather than domestic and unpaid labour that often provide vital care functions. Box 2 outlines some of the ways in which the nature of paid work might change over the next decade and beyond.
The joint academies' workshop was concerned with novel technologies that have the potential to extend an individual's capacities beyond their current limits. This working definition encompasses restorative enhancements and those that could take individuals 'beyond the norm', by which we mean both beyond an individual's 'norm' and beyond the 'norm' of current human limits. ${ }^{2}$ In considering implications for the future of work, we felt it important to include the whole spectrum of enhancement technologies.

In considering the application of human enhancement to work, much discussion at the workshop focused on its potential role in increasing the access of disabled people to work. The Department of Work and Pensions has estimated that there are over 10 million disabled people in the UK. ${ }^{3}$ Over 6 million report significant problems with mobility, a similar number with lifting and carrying, and over 2 million report problems with dexterity and/or coordination. Of the people living with disabilities, about $50 \%$ are of working age.

However, employment rates among individuals with a disability that limits their daily activities (DDA disabled) are well below the national average for those who are not DDA disabled (45.6\% compared with $76.2 \%$ ), with the lowest rates for those with depression, mental illness and learning difficulties. ${ }^{4}$ The use of enhancement technologies that restore capacity could therefore have significant implications for this community, and, commonly, technologies used to enhance healthy individuals often emerge from those that were originally designed to be restorative.

1 Cracknell R (2010). The ageing population. http://www.parliament.uk/documents/commons/lib/research/key issues/Key\%20Issues\%20 The\%20ageing\%20population2007.pdf

Defining the 'norm' is complex. For example, in the elderly, cognition may be normal for the age but cognitive performance may have declined from performance when young. Additionally, for example, in spectrum disorders, extreme conditions may be clearly diagnosable but those on the borderline may blend with healthy controls (e.g. as for attention-deficit-hyperactivity disorder).

3 Office for Disability Issues, Department of Work and Pensions (2001). Disability prevalence estimates 2009/10. http://odi.dwp.gov.uk/docs/res/factsheets/disability-prevalence.pdf

4 Office for National Statistics (2011). People with disabilities in the labour market - 2011. http://www.ons.gov.uk/ons/dcp171776_242963.pdf 
Our working definition includes all forms of enhancement that directly alter the individual, but excludes the wider environment, i.e. alterations to the environment itself that enhance human interactions with it. There are interesting developments in efforts to enhance the environment in which people work, and moves towards assisted living (i.e. assistance with the activities of daily living) bring technical interventions that could allow people to stay in their own home for longer, particularly in old age. However, these were outside of the remit of this particular workshop. Education is relevant in its role in preparing individuals for work and ongoing training throughout the life course (e.g. lifelong learning), but was not considered a focus of this meeting.
This report seeks to capture the themes and questions that emerged from the workshop and does not necessarily represent the views of the four host academies. The report will be of interest to policy-makers, researchers in science and engineering, experts in the social sciences and humanities, research funders, industry, investors and publics, both within the UK and internationally. Chapters 2 and 3 explore the science and engineering developments that could give rise to physical and cognitive enhancement. Opportunities and challenges relating to investment and commercialisation are outlined in Chapter 4. Chapter 5 discusses possible implications for the future of work and society. Potential policy and regulatory implications are considered in Chapter 6. 


\section{Box 2 Examples of potential changes to the nature of work in future}

\section{Composition and diversity of the workforce}

Owing to the ageing population, we are likely to see individuals working at an older age, resulting in a more multigenerational workforce. Different generations are likely to have different attitudes towards, and experiences of, technology. Further changes to, for example, gender balance and migration, will combine to generate additional diversity.

\section{Working practices}

Workers are likely to have increasing expectations of, and access to, flexible working. This might be in terms of working hours, location and further changes to the global nature of business and work.

\section{Evolving nature of work}

The UK has seen a transition from the production of goods to the provision of information and services, which is set to continue. Different skills will be expected from employees, which could impact on health and safety, such as the nature of work-associated illnesses.

\section{Economics}

Global economies will be in recovery for several years. We are likely to see further growth in international competition and evolution of the form and structure of organisations.

\section{Disease trends}

The conditions that will have greatest impact on the working population will be musculoskeletal disorders and mental illness. Sensory disorders will remain prevalent and lifestyle diseases will continue to rise. As the nature of, and attitudes towards, illnesses change, and as medicine progresses, it will become much more likely that individuals will work while in ill health or with disabilities.

\section{The role of work}

Work is increasingly seen as a source of wellbeing. Being in work is beneficial to physical and mental wellbeing. Employers are assuming a greater degree of responsibility for the welfare of their employees and are well placed to promote a healthy lifestyle among workers. 


\section{Cognitive enhancement}

\section{Overview}

There are several ways to enhance cognition in humans. Education and physical exercise are two well-established cognition enhancers not considered in detail here. Over the next decade, the ageing population will render efforts to restore and maintain cognition increasingly important. Emerging approaches include the following:

- Cognition enhancing drugs used to treat individuals with neuropsychiatric disorders could also improve mental faculties such as memory and concentration in healthy individuals, enabling them to work more efficiently or for longer.

- Drugs could also facilitate cognitive maintenance, which could be particularly beneficial to the ageing workforce. Revealing the optimal timing of treatment onset, as well as the risk factors that could facilitate cognitive decline, will be invaluable.

- Cognitive training delivered by computer may be able to improve learning, and research into the ways in which the brain responds to training is beginning to inform software design. Cognitive training will be most useful if it can provide transferable improvements, rather than just better performance on specific tasks.

- Brain stimulation, particularly non-invasive techniques, might facilitate improved learning and training outcomes, but further research will be needed to reveal how it should be used.

- Collective cognition could also facilitate enhanced performance at work. The rise in ubiquitous communications technologies over the past decade has changed how we work and is likely to improve efficient and inexpensive coordination and knowledge-sharing. This brings new opportunities to harness technology to boost the power of a collective network to solve complex problems. Individuals will in turn use the outputs of collective efforts to enhance their individual performance.

\section{Pharmacological cognitive enhancement}

Recent developments in our approaches to neuroscience and mental health policy have seen a shift in focus from attempts to treat chronic, relapsing mental health disorders to the prevention and early detection of such disorders. ${ }^{5}$ Research focuses on successful and resilient neurodevelopment. ${ }^{6}$ Participants emphasised that preserving mental wellbeing in this way is important to enabling people to stay in work. This was a key feature of the
2008 Foresight project on 'Mental Capital and Wellbeing' by the UK Government Office for Science. ${ }^{7}$

\section{Cognitive maintenance and restoration}

Research on degenerative diseases such as dementia reflects a shift in focus to prevention. Life expectancy increases linearly by two years every decade. ${ }^{8}$ There are currently 820,000 people with dementia in the UK and this is expected to double over the next 30 years. ${ }^{9}$

\footnotetext{
Beddington J, et al. (2008). The mental wealth of nations. Nature 455, 1057-1060.

Sahakian BJ, Malloch G \& Kennard C (2010). A UK strategy for mental health and wellbeing. Lancet 375, 1854-1855.

Foresight Mental Capital and Wellbeing Project (2008). Final project report - executive summary. The Government Office for Science,

Population Reference Bureau (2006). The future of human life expectancy: have we reached the ceiling or is the sky the limit?

www.prb.org/pdf06/NIA FutureofLifeExpectancy.pdf

WwW.prb.org/pdf06/NIA FutureofLifeExpectancy.pdf Kingdom. http://www.dementia2010.org/reports/Dementia2010Full.pdf
} 
Current medications such as cholinesterase inhibitors target disease symptoms with the aim of delaying cognitive decline. However, novel medications that improve episodic memory more effectively, and neuroprotective medications, are needed. New approaches target the molecular pathways, such as the amyloid cascade in the brain, or the formation of insoluble tau protein, but we are yet to find a treatment that truly modifies the degeneration. It may be that the hypotheses relating to disease processes need to be reconsidered, as other factors, such as inflammation, may be more important than previously thought. However, Professor John O'Brien, Professor of Old Age Psychiatry at Newcastle University, told the workshop that there is a growing consensus that we are currently identifying and treating patients at too late a stage. It is likely that there is a 10-20 year asymptomatic stage before disease onset; targeting this might hold the key to improving methods of cognitive maintenance. This theory not only reflects our greater understanding of molecular mechanisms causing dementia but also how risk factors such as diet and activity and vascular risk during middle age affect health later in life; we must understand the risk factors for cognitive decline to improve our management of it. Professor O'Brien reported that patients seek disease stabilisation and cognitive maintenance. In moving forward, research must firstly look to further our understanding of the fundamental science of neurodegeneration, and secondly reveal the optimal timing for the delivery of such treatments, which will depend on whether they seek to prevent the underlying molecular changes, or modify risk factors.
Cognitive-enhancing drugs have not only been developed for the treatment of neurodegenerative diseases, but also for other neuropsychiatric disorders, including attentiondeficit-hyperactivity disorder (ADHD) and schizophrenia. Such disorders are characterised by cognitive manifestations including attentional biases, aberrant learning, memory impairments, dysfunctional reward systems and a lack of top-down cognitive control by the prefrontal cortex. ${ }^{10}$ Professor Barbara Sahakian FMedSci, Professor of Clinical Neuropsychology at the University of Cambridge, told the workshop that it is most often the decline in these cognitive abilities that inhibits individuals with depression or schizophrenia from returning to work. ${ }^{11,12}$ Cognitive enhancers can treat cognitive disabilities and improve mental capital and wellbeing, but also an individual's quality of life and their ability to work. ${ }^{13}$

The annual costs of these kinds of disease, including those related to lost earnings and lost productivity, mean that there are economic benefits to effective treatment of all neuropsychiatric disorders. It is estimated that by 2026 , the cost of mental health disorders in England will rise to $£ 88.4$ billion, nearly half of which will be as a result of lost earnings (£40.9 billion). ${ }^{14}$

\section{Cognitive enhancement of healthy individuals}

Box 3 outlines the kinds of cognitive enhancer on the market. Professor Sahakian reported that we are increasingly seeing some of these drugs used by healthy individuals, among whom there is evidence that they do improve

10 Sahakian BJ (2011). American College of Neuropsychopharmacology 50th Annual Meeting, 4 December 2011.

11 Scoriels L, et al. (2012). Effects of modafinil on cognitive functions in first episode psychosis. Psychopharmacology 220(2), 249-258.

1 Clark L, Chamberlain SR \& Sahakian BJ (2009). Neurocognitive mechanisms in depression: implications for treatment. Annual Review of leuroscion

13 Morein-Zamir S \& Sahakian BJ (2011). Pharmaceutical cognitive enhancement. In Illes J \& Sahakian BJ, eds. (2011) Oxford Handbook of Neuroethics. Oxford University Press, Oxford UK.

14 King's Fund (2008). Paying the Price: The cost of mental health care in England to 2026. http://www.kingsfund.org.uk/publications/paying the_price.html 
performance. For example, methylphenidate improves short-term (or working) memory in healthy volunteers, as well as in those with ADHD. ${ }^{15,16}$ It also increases the 'efficiency' of the prefrontal cortical network in healthy volunteers. ${ }^{17}$ Furthermore, stimulant drugs exert their effects in a baseline-dependent manner, so stimulants will improve low performance in individuals regardless of whether the individual is a healthy volunteer or has ADHD. ${ }^{18}$ It has been shown that modafinil improves planning in healthy volunteers. ${ }^{19}$

Research has explored whether cognitive enhancers might be of use in workers who are sleep deprived. A 2011 study found that modafinil reduces impulsive behaviour and improves cognitive flexibility in sleep-deprived doctors. ${ }^{20}$ This group of individuals often use caffeine to improve alertness, which in higher doses is accompanied by side effects such as tremor and heart palpitations. These effects are not seen with modafinil.

Several surveys have investigated trends in the use of cognitive enhancers among student populations, with varying results, but Professor Sahakian reported that $16 \%$ may be a realistic estimate for the prevalence of use among students in the USA. ${ }^{21}$ There is also evidence that use among healthy individuals is rising among school students, and stimulant prescription rates in England have been rising steadily from 220,000 in 1998 to 418,300 in 2004. ${ }^{22}$ Research indicates that some academics also make use of enhancers such as modafinil and for a variety of reasons, e.g. to overcome jetlag and to improve productivity for particularly challenging tasks. ${ }^{23}$ An online poll by the journal Nature found that of 1,400 respondents from 60 countries, one in five said they had used drugs for non-medical reasons as a cognitive enhancer. ${ }^{24}$

The Royal Society concluded in 2011 that education is the 'most broadly and consistently successful cognitive enhancer'. 25 However, the attraction of cognitive enhancement might lie in gaining a small but significant competitive edge. The Academy of Medical Sciences reported in 2008 that small percentage increments in performance can lead to significant improvements in functional outcome; it is conceivable that a $10 \%$ improvement in memory score could lead to an improvement in an A-level grade or degree class. ${ }^{26}$ The attraction may also stem from the increased pleasure experienced in performing a task. There is evidence that cognitive-enhancing drugs such as modafinil can increase motivation and the pleasure gained from performing routine cognitive tasks, compared with placebo. ${ }^{27}$

15 Elliott R, et al. (1997). Effects of methylphenidate on spatial working memory and planning in healthy young adults. Psychopharmacology 131, 196-206.

16 Turner DC, et al. (2005). Neurocognitive effects of methylphenidate in adult attention-deficit/hyperactivity disorder. Turner DC, et al. (2005). Neurocognitive

17 Mehta MA, et al. (2000). Methylphenidate enhances working memory by modulating discrete frontal and parietal lobe regions in the human brain. The Journal of Neuroscience 20, RC65.

18 Del Campo N, Müller U \& Sahakian BJ (2012). Neural and behavioral endophenotypes in ADHD. Current topics in Behavioural Neurosciences 11, 65-91.

19 Turner DC, et al. (2003). Cognitive enhancing effects of modafinil in healthy volunteers. Psychopharmacology 165, 260-269.

20 Sugden C, et al. (2011) Effect of pharmacological enhancement on the cognitive and clinical psychomotor performance of sleep-deprived doctors: a randomized controlled trial. Annals of Surgery 255, 222-227.

21 Babcock Q \& Byrne T (2000). Student perceptions of methylphenidate abuse at a public liberal arts college. Journal of American College Health 49, 143-145.

22 Parliamentary Office of Science and Technology (2007). Better brains. http://www.parliament.uk/briefing-papers/POST-PN-285.pdf

23 Morein-Zamir S \& Sahakian BJ (2007). Professor's little helper. Nature 450, 1157-1159.

24 Maher B. (2008). Poll results: look who's doping. Nature 452, 674-675.

25 Royal Society (2011). Brain waves module 2. Neuroscience: implications for education and lifelong learning. http://royalsociety.org/uploadedFiles/Royal Society Content/policy/publications/2011/4294975733.pdf

26 Academy of Medical Sciences (2008). Brain science, addiction and drugs. http://www.acmedsci.ac.uk/download.php?file=/images/ publication/Report.pdf

27 Müller U, et al. (2012) Effects of modafinil on non-verbal cognition, task enjoyment and creative thinking in healthy volunteers. Neuropharmacology, http://dx.doi.org/10.1016/j.neuropharm.2012.07.009 


\section{Box 3 Examples of cognitive enhancers currently in common use}

Methylphenidate (Ritalin) increases the synaptic concentration of the neurotransmitters dopamine and noradrenaline by blocking their reuptake.

Atomoxetine (Strattera) is a relatively selective noradrenaline reuptake inhibitor. Although Ritalin has low abuse potential when prescribed correctly, its action on the dopaminergic system brings a risk of substance misuse. By not acting on dopamine, Atomoxetine is not accompanied by such risks.

Modafinil (Provigil) is an atypical stimulant. Its cognitive enhancing effects are likely to be due to effects on noradrenaline and possibly dopamine.

Some cognitive-enhancing drugs do not produce extreme changes in mood that usually accompany recreational use, such as a 'high' or 'rush', and do not lead to obvious physical dependence. ${ }^{28}$ This applies to drugs such as atomoxetine and modafinil. ${ }^{29,30}$

However, it is not clear that such enhancers will benefit all types of work. For example, participants at the workshop discussed how the effects on creativity are not clear. Research yields mixed results, but there is evidence that, for at least some cognitive-enhancing drugs, such as stimulants, effects might depend on the baseline creativity of an individual: increasing it in lower performing individuals, but inhibiting creativity in naturally high performing individuals. ${ }^{31}$ It is likely that some enhancements will be more useful to some types of worker, for example shift workers, and that there will be individual differences in the effects of each enhancement. Where drugs are concerned, in future it might be possible to use techniques such as pharmacogenomics to determine which individuals might benefit from the use of specific cognitive-enhancing drugs.

Cognitive enhancers are a significant area for pharmaceutical investment. As our understanding of the brain improves, it may inform the development of new enhancers, for example the synaptic changes required for memory encoding.

\section{Non-pharmacological cognitive enhancement}

\section{Brain stimulation}

There are also several non-pharmacological options for enhancing cognition. Deep brain stimulation has offered very effective symptomatic relief in some patients with Parkinson's disease, and the technique may have potential in treatment-resistant depression. ${ }^{32}$ However, such an invasive technique is unlikely to have widespread applications. Dr Roi Cohen Kadosh, Wellcome Research Career Development Fellow at the University of Oxford, told the workshop that non-invasive brain stimulation could be a

28 Royal Society (2011). Brain Waves module 1. Neuroscience, society and policy.

http://royalsociety.org/uploadedFiles/Royal Society Content/policy/publications/2011/4294974932.pdf

29 Chamberlain SR, et al. (2007). Atomoxetine improved response inhibition in adults with attention deficit/hyperactivity disorder. Biological Psychiatry 62, 977-984.

30 Scoriels L, Jones PB \& Sahakian BJ (2012). Modafinil effects on cognition and emotion in schizophrenia and its neurochemical modulation in the brain. Neuropharmacology. http://dx.doi.org/10.1016/j.neuropharm.2012.07.011

31 Farah MJ (2008). When we enhance cognition with Adderall, do we sacrifice creativity? A preliminary study. Psychopharmacology 202 541-547.

32 Holtzheimer PE (2012). Subcallosal cingulate deep brain stimulation for treatment-resistant unipolar and bipolar depression. Archives of General Psychiatry 69, 150-158. 
more applicable technique and of widespread use in the next years. The most used noninvasive transcranial stimulation methods are transcranial magnetic stimulation, in which a magnetic coil is placed above part of the skull to deliver magnetic pulses to the brain area beneath the skull, and to induce action potentials; and transcranial electrical stimulation, in which low electrical currents are applied to the skull through one or more electrodes, to modulate neuronal excitability in brain areas beneath the skull. Transcranial electrical stimulation offers the most possibilities for cognitive enhancement at home, office, clinics and educational institutes as it is a relatively inexpensive, portable and painless method of enhancing cognitive abilities by modulating brain activity. Currently the data from low electrical stimulation studies do not reveal any risk or major side effects. There is evidence that transcranial direct electrical stimulation shows potential in enhancing the learning and cognition of healthy adults and those with neurological impairment, and its effects could be relatively long-term in nature (e.g. between six and twelve months after treatment). $33,34,35,36$ More research is required to establish how useful it might be, especially in the elderly and in children with atypical development, where experimental evidence is relatively scarce. It is also not clear whether improvements in performance are transferred to other tasks, and research is required particularly to determine optimal use, which might differ for different populations, for example:

- Point at which the technique should be used during learning.

- Duration, number of repetitions and timing of stimulation (e.g. before or during the task).
- Position on the skull for the apparatus to be placed and whether this is task-dependent.

- Intensity of stimulation and whether this varies, for example between tasks.

As well as stimulating the brain, monitoring its activity may offer new opportunities to restore brain function in some disorders. Participants noted that methods in neurofeedback are being explored for the treatment of several cognitive disorders. The technique makes use of sensors placed on the scalp to record central nervous system activity (e.g. by electroencephalography or functional magnetic resonance imaging (fMRI)), which provide immediate feedback about brain activity in a way that can be used to modulate training and deliver improvements in physical, emotional or cognitive states. Research suggests that neurofeedback is an effective intervention to address the inattention, impulsivity and hyperactivity experienced by patients with ADHD and may have applications to other disorders, including Parkinson's disease and schizophrenia. 37,38,39

\section{Cognitive training}

Another way in which technology could support the development of cognitive capabilities is through cognitive training. More efficient learning could be of value in the education and training that prepare individuals to work and enable ongoing improvement. Workshop participants highlighted particular examples that will be increasingly important as the nature of work changes, such as language learning. Dr Paul Howard-Jones, Senior Lecturer in Education at the University of Bristol, told the workshop that there are three key characteristics of digital technology that make it

33 Cohen Kadosh R, et al. (2010). Modulating neuronal activity produces specific and long lasting changes in numerical competence. Current Biology, 20, 2016-2020.

34 Dockery CA, et al. (2009). Enhancement of planning ability by transcranial direct current stimulation. The Journal of Neuroscience, 29, 7271-7277

35 Holland R, et al. (2011). Speech facilitation by left inferior frontal cortex stimulation. Current Biology 21(16), 1403-1407.

36 Fridriksson J, et al. (2011). Transcranial direct current stimulation improves naming reaction time in fluent aphasia: a double-blind, sham-controlled study. Stroke 42(3), 819-821.

Arns M, et al. (2009). Efficacy of neurofeedback treatment in ADHD: the effects on inattention, impulsivity and hyperactivity: a meta-analysis. Clinical EEG and Neuroscience $\mathbf{4 0}, 180-189$.

38 Subramanian $\mathrm{L}$, et al. (2011). Real-time functional magnetic resonance imaging neurofeedback for treatment of Parkinson's disease. Subramanian L, et al. (2011). Real-time function

39 Ruiz S, et al. (2011). Acquired self-control of insula cortex modulates emotion recognition and brain network connectivity in schizophrenia. Human Brain Mapping doi: 10.1002/hbm.21427. 
well-suited to supporting cognitive training:

- It is adaptive: technologies can be programmed to tailor experiences to the individual.

- It is responsive: technologies can provide immediate feedback.

- It is patient: activities can be repeated limitlessly.

Two main types of initiative look to enable brain training. Commercial 'brain training' software targets multiple faculties, including memory (short term, visuospatial or episodic), executive control (attention switching) and visuomotor skills. Laboratory studies normally make use of bespoke software and specifically target working memory. Although commercial training software is generally unevaluated, there is growing evidence that software used in laboratory studies can improve cognition. However, generating improvements that are transferable to tasks that have not been the focus of training presents a significant challenge.

These technologies, particularly those that are commercially available, target multiple audiences, from young to old and including those with and without cognitive impairment. Research indicates that cognitive training might support cognitive maintenance. One study found improvements in memory, reasoning and speed of processing in individuals over 65 years of age. ${ }^{40}$ However, this was not transferred to a measurable improvement in real-life tasks, although there were fewer self-reported difficulties after the trial. Other studies have indicated that such transfer might be possible. Improvements in performance on cognitive tasks within this same age group have been reported, which subsequently translated into improvements on generalised measures of memory and attention, for which participants had not been trained. ${ }^{41}$ Small-scale studies also indicate that regularity may aid effectiveness: elderly participants playing training games for 15 minutes per day for at least five days a week saw improvements in executive functions and processing speed. ${ }^{42}$ In fact, regular training may improve executive functions across all age groups in a transferable manner. ${ }^{43}$

The key to improving training methods again lies in embracing a new approach: a new science of learning, in which interdisciplinary collaboration is essential to maximising the potential of cognitive training. ${ }^{44}$ Psychology, neuroscience, education and the use of machine learning must all interact to generate an iterative design loop where, for example, neuroscience provides insights that inform the development of technologies, which then provide a platform on which further neuroscience studies can be performed. Although such collaborations are still at a very early stage and can yield apparently conflicting findings, studies are beginning to offer insights into the underlying neural mechanisms of cognitive training. Such insights could inform better software design and offer opportunities to develop training that delivers better transfer of skills.

Current evidence suggests that, during training, activity decreases in regions of the brain concerned with general processes, for example attentional control, but increases in regions that perform task-specific functions. Fourteen hours of training over five weeks was associated with increased brain activity on a working memory task and changes in dopamine receptor D1 binding potential in the same areas. ${ }^{45}$ Further, studies are beginning to reveal the brain

40 Ball K, et al. (2002) Effects of cognitive training interventions with older adults: a randomized controlled trial. Journal of the American Medical Association 288, 2271-2281.

1 Smith $\mathrm{E}$, et al. (2009). A cognitive training program based on principles of brain plasticity: results from the Improvement in Memory with Plasticity-based Adaptive Cognitive Training (IMPACT) Study. Journal of the American Geriatrics Society 57, 594-603.

42 Nouchi R, et al. (2012). Brain training game improves executive functions and processing speed in the elderly: a randomized controlled trial. PLOS ONE, doi:10.1371/journal.pone.0029676

43 Karbach J \& Kray J (2009). How useful is executive control training? Age differences in near and far transfer of task-switching training. Developmental Science 12, $978-990$.

44 Meltzoff AN, et al. (2009). Foundations for a new science of learning Science 325, 284-288.

45 Olesen PJ, Westerberg H \& Klingberg T (2004) Increased prefrontal and parietal activity after training of working memory. Nature Neuroscience $\mathbf{7}(\mathbf{1}), 75-79$. McNab F, et al. (2009) Changes in cortical dopamine D1 receptor binding associated with cognitive training. Science 323(5915), 800-802. 
areas involved in performing particular tasks. For example, comparing the brain activity of children with developmental dyscalculia (difficulty with understanding and using numbers) with that seen in children without this disorder, while playing mathematics games, can reveal differences in brain activity. ${ }^{46}$ This information can in turn inform the evaluation of the training game in question and aid its further development. In elderly individuals, fMRI studies have revealed that computer-based training can lead to changes in brain structure in areas known to deteriorate with age. ${ }^{47}$

These studies use games designed to enhance cognition, and a variety of longitudinal, experimental and correlation studies have shown that playing action video games can enhance skills in a manner that is transferable to other contexts. ${ }^{48}$ These effects are seen in seasoned gamers, as well as in non-game players ${ }^{49}$, and can include the following:

- Performance on visuomotor tasks.

- Switching of visual attention.

- Suppression of visual distraction.

- Inference of an action's probable outcome.

- Contrast sensitivity (which is a primary factor limiting sight).

- Affective response (both aggressive and prosocial behaviour, such as empathy).

Thus, video games might have potential applications to training for work. Research with surgeons indicates that those who regularly play video games pick up certain surgery skills more quickly and that training on video games appears to improve performance. ${ }^{50}$ Studies also indicate that gaming can provide transferable skills to army pilots. ${ }^{51}$ Interdisciplinary approaches are again key to progress, and although the neuroscience of video gaming is still in its infancy, studies are showing promise in revealing the processes involved in training.

Video games may be good tools for cognitive training because they are so engaging. In fact, they can be addictive, triggering similar neuronal networks to those stimulated in drug and gambling addicts. ${ }^{52}$ It is this property that may make them useful because the brain's dopaminergic reward system, which is stimulated by these games, is implicated in plasticity and thus in learning. Studies in neuroscience are beginning to explore the plasticity involved in the transfer of trained abilities to real-world tasks, as well as revealing how different training strategies (e.g. focusing on individual elements of a task or a whole task in general) might impact on learning. 53,54 For example, games could be designed so that the reward element is maximised to increase the likelihood of effective learning. Video games could also offer promise in cognitive maintenance. Research in patients with Alzheimer's disease indicates that brain training games might be more effective than traditional psychostimulation methods in reducing both cognitive decline and depressive symptoms. 55

This interdisciplinary approach has the potential to lead to better incorporation of video game processes with learning and training processes.

46 Kucian K, et al. (2011). Mental number line training in children with developmental dyscalculia. Neuroimage 57, 782-795.

47 Lovden M, et al. (2010). Experience-dependent plasticity of white-matter microstructure extends into old age. Neuropsychologia 48, 3878-3883.

48 Bavelier D, et al. (2011). Brains on video games. Nature Reviews Neuroscience 12, 763-768.

49 Green CS \& Bavelier D (2003). Action video game modifies visual selective attention. Nature 423, 534-537.

50 Lynch J, Aughwane P \& Hammond, TM (2010). Video games and surgical ability: a literature review. Journal of Surgical Education 67, 184-189.

51 Gopher D, Weil M \& Bareket T (1994). Transfer of skill from a computer game trainer to flight. Human Factors 36, 387-405.

$52 \mathrm{Han} \mathrm{DH}$, et al. (2011). Brain activity and desire for internet video game play. Comprehensive Psychiatry 52, 88-95.

53 Howard-Jones PA, et al. (2011). Toward a science of learning games. Mind, Brain and Education 5, 33-41.

54 Voss MW, et al. (2012). Effects of training strategies implemented in a complex videogame on functional connectivity of attentional networks. Neuroimage 59, 138-148.

55 Fernandez-Calvo B, et al. (2011). Efficacy of cognitive training programs based on new software technologies in patients with AlzheimerType dementia. Psicothema 23, 44-50. 


\section{Collective enhancement}

Although the term 'enhancement' traditionally implies that individuals are the target, we could also consider it in terms of collective cognition. Much technology already exists that might enable this kind of enhancement. Technological development is offering the potential to create a truly remarkable range of applications to enhance human cognition. Such development sees disciplines converge, particularly device engineering, computer science, psychology and neuroscience. Interdisciplinary working will be key to exploiting this potential.

According to Moore's law, the number of transistors that can be placed in a microprocessor chip doubles approximately every 18 to 24 months. The degree of memory density that can be achieved in computing devices is also doubling at similar rates. This steady progress makes developments in engineering very predictable. We can fairly accurately predict what we will be able to design and when over the next decade, and beyond. Consequently, we can look to draw conclusions about what the implications might be.

Professor Nigel Shadbolt FREng, Professor of Artificial Intelligence at the University of Southampton, told the workshop that, as a result, we are moving towards a new kind of augmented intelligence, defined by harnessing both decision support systems and ambient computing. To maximise the potential of augmented intelligence, decision support systems must be supplemented by a computing 'fabric' - the digital environment within which we are now immersed - that enables us to harness collective cognition routinely. This kind of enhancement can support humans to solve problems individually and collectively that were previously beyond our capacity.
A good example, so routine now that we do not necessarily recognise it as enhancement, is provided by the development of internet search engines. ${ }^{56}$ These facilities were significantly improved by the introduction of PageRank, an algorithm that assigns relative importance to web pages based on connections that users make between them. This process aims to contextualise information and optimise its relevance to the user. The result, apart from the creation of Google itself, is near instantaneous access to billions of pages of information across the Web. This has already transformed the range of information we can individually and collectively draw on, and with developments in next-generation technologies such as the Semantic Web we can anticipate information retrieval that is even more customised to our needs. 57

Uniting decision support systems with ambient computing can also help us to harness collective intelligence to augment, for example, problem solving through content creation. After the earthquake in Haiti, the rescue efforts required accurate maps of the capital, Port-au-Prince. However, existing maps did not provide sufficient detail and much of the landscape had changed due to the earthquake. Mappers from across the world used a combination of fresh satellite imagery and open-source software using open standards to generate the missing maps. This was achieved by providing relief workers on the ground with the ability to upload their Global Positioning System (GPS) data along with annotations they had made about the routes they had taken that day. The result was the crowd-sourced creation of a detailed image of the city layout within 12 days. ${ }^{58}$ No less impressive is the collective content generation that results in resources such as Wikipedia, 
where the core articles compare favourably to the very traditional encyclopaedias. ${ }^{59}$ Collective intelligence of this kind also brings the advantage of resilience in the face of attack or misinformation.
Professor Shadbolt reported that the most successful methods for harnessing collective intelligence to solve complex problems will rely on combining conventional computation with social computation, as outlined in Figure 1.

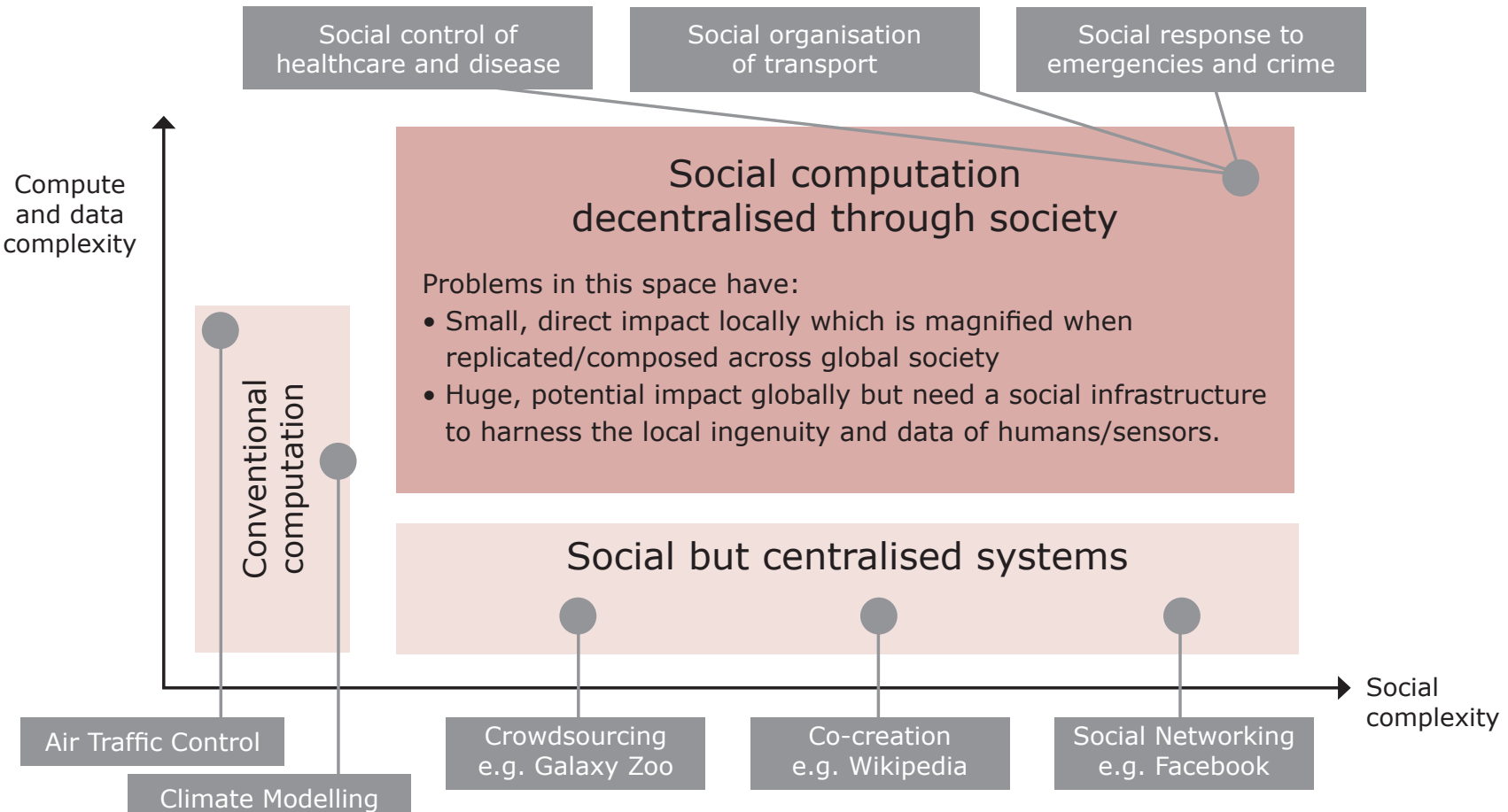

Figure 1: Combining the power of social computation with conventional computation can enable small, direct, local impacts that could potentially have huge global impacts. ${ }^{60}$ Compute complexity describes the computing resources required to perform the analysis.

Of course, such technological developments can also benefit individuals. For example, Professor Shadbolt reported that within 15 years, we will have devices small enough to record an individual's entire experience throughout their life as a continuous video feed, effectively providing a 'life logging' function. ${ }^{61}$ Such a device could be of use to individuals with memory disorders. ${ }^{62}$
In clinical trials, patients show better memory recall and consolidation when presented with images than when using written logs. 63 Mixed or augmented reality will be routine in the next decade. For example, Google is developing glasses that they anticipate will give the user real-time information about their environment, such as encyclopaedic knowledge, in a similar way to the current

59 Giles, J (2005) Internet Encyclopedias go head to head. Nature 438, 900-901

60 Figure reproduced with the permission of Professor Nigel Shadbolt.

61 O'Hara K et al. (2006). Memories for life: a review of the science and technology. Journal of the Royal Society Interface 3(8), $351-365$.

62 De Jager D, et al. (2011). A low-power, distributed, pervasive healthcare system for supporting memory. In, 1 st ACM MobiHoc Workshop on De Jager D, et al. (2011). Alow-

63 Hodges S, et al. (2006). SenseCam: a retrospective memory aid. In: 8th International Conference of Ubiquitous Computing. 
mapping software that uses augmented reality on mobile devices. ${ }^{64}$ Immersive technology that substitutes reality altogether has been discussed for decades and now has an established role in training, for example, jet fighter pilots. As we approach an age where we can deliver information of unsurpassed fidelity, substituting reality in this way could become a lot more efficient and applicable to other situations. In future, we will see an evolving information ecosystem, ubiquitous in our everyday lives and delivered by mobile and pervasive computing.

This offers unprecedented opportunities to harness collective cognition, and the social aspect of computing will be a key element of driving progress.

Despite the immense growth in technological development, there is little empirical data on how cognition is improved with any of these tools. Participants discussed the fact that such tools can enter the market without needing to demonstrate any effects of this nature, meaning that there is currently little motivation to collect data on efficacy. With many of the technologies described, the process of finding and presenting results is not entirely transparent to the user. Where search engines are used, biased results could be presented to the user, unknown to them if they do not understand the PageRank process or the process by which search results are further filtered. Cognition is enhanced, but there are questions about the extent to which this can be considered enhancement if users are remote from the process. Furthermore, not understanding how an enhancement works arguably compromises the use of that enhancement, and the user's ability to optimise their use of it.

\section{Impacts on employee motivation}

Participants also discussed the use of tools such as drugs or brain stimulation in relation to mood enhancement for individuals who are not currently suffering from a mood disorder. For example, the use of cognition enhancers or brain stimulation might be of interest to employees who find aspects of their work less stimulating.

Many of the enhancements discussed in this chapter have obvious ethical and social implications, which are discussed in Chapter 5. 


\section{Physical enhancement}

\section{Overview}

To date, physical enhancement has been developed primarily with a focus on restoration, although over the next decade we are likely to see this extend to applications in healthy individuals. Developments include the following:

- As the average age of the working population rises, individuals are likely to seek to maintain or restore declines in sensory perception. Better-quality devices like hearing aids will support prolonged auditory abilities, but could also be useful to individuals with normal hearing in challenging situations, such as in the military. Equally, new techniques to restore and maintain vision are in development, such as retinal implants, gene transfer and replacing photoreceptors in the eye.

- Technologies external to the body can support restoration of mobility and limb function, and future applications in healthy individuals might include those whose jobs involve manual labour. Design of devices like bionic limbs and exoskeletons must overcome the traditional challenges of user control, energy efficiency and usability if they are to become more automated and easy-to-use, and thus more accurately mimic or surpass the functionality of human limbs.

- Tissue engineering and regenerative medicine are offering new opportunities to replace degenerating tissues. Less complex applications, such as bone and joint tissues, are entering clinical trials and we are seeing progress in more complex tissues like tracheas. The most complex cases will produce entire organs, but less involved techniques that target specific parts of an organ might turn out to be sufficiently effective. Research to integrate stem cell work with cardiac pumps is another avenue, which might also be applied to other organs.

- Good nutrition is clearly vital to health and wellbeing, and there may be particular nutritional approaches that benefit specific aspects of performance, such as stamina, strength and recovery time. Future applications could be improved by determining the neuronal basis of overcoming fatigue.

- Cosmetic enhancement could be appealing to some members of an ageing workforce, in which younger appearance might be believed to have implications for one's employment prospects.

Although we consider somatic gene therapy in this chapter, which is currently being used for restoration and could be adapted for enhancement, we deliberately chose to exclude germ-line gene modification because this is unlikely to be considered a reasonable approach for technical and ethical reasons for at least the next 10 years. ${ }^{65}$ (It is also prohibited in the UK and all countries with regulation covering human fertility and embryo research.)

\section{Sensory enhancement}

Cognitive and physical enhancements overlap when we consider enhancing human senses. Restoring lost functionality and delaying degeneration is of particular interest to an ageing population. In such contexts, it is difficult to identify the boundary between restoration and enhancement: for example, an individual may have abilities that are 
considered normal for someone of their age, but they may consider the reduced capacity as a disability. There may also be motives to enhance non-disabled individuals, for example to hear or see in challenging situations.

\section{Human hearing}

Hearing loss affects individuals increasingly with age. For the adult population as a whole, hearing loss of 25 decibels or more affects $16 \%$ of the population. However, progressive decline in hearing from the age of 20 causes this figure to rise to $37 \%$ in those aged between 61 and 70 years, and further to $60 \%$ in those between 71 and 80.66 Professor Brian Moore FRS FMedSci, Professor of Auditory Perception at the University of Cambridge, outlined that, in the context of work, hearing enhancement might have the following benefits:

- Allow older people to continue functioning successfully in the workplace, by effective restoration or maintenance.

- Enhance hearing for people with normal perception in noisy or reverberant situations.

Most hearing loss arises in the cochlea. Individuals experience difficulties in perceiving low-level sounds and a reduced range of sound intensities over which sounds are heard comfortably, accompanied by a reduced ability to differentiate between the different frequencies in complex sounds. This results in an impaired ability to understand speech, particularly where background noise is present.

Cochlear implants, which have been developed and refined over the past 40 years, are surgically implanted to restore some of the function of the cochlea, for people with profound or total hearing loss. They often enable patients to understand speech and to identify environmental sounds, although the quality of sounds is not as good as with natural hearing. Implants consist of an external microphone, speech processor and transmitter, connected to an internal receiver and stimulator. The stimulator converts signals into electric impulses, which are sent through an internal cable to an array of electrodes along the length of the cochlea.

Hearing aids have become increasingly sophisticated to try to overcome some of the problems of hearing loss. For example, with multi-channel compression, sounds are split into several frequency bands and each one is amplified to a different extent depending on the frequency and the input sound level. This addresses issues with the limited range of audible and comfortable sound intensities, but there are limitations in practice. Other developments look to improve the perception of speech in background noise. For example, hearing aids make use of directional microphones to detect sounds selectively from the front. Signals can be further enhanced using digital processing and by using bilaterally fitted hearing aids (one on each ear) that can communicate with each other and be remotely controlled. In the future, remote controls could be replaced with a sensor that detects brain signals, but this is many years away.

A novel method of sound delivery for those with mild to moderate hearing loss is incorporated in the EarLens system. Sound is picked up by a microphone in or near the ear canal, and audio signals and power are transmitted by a laser to a receiver and transducer that vibrates the eardrum directly. This provides high-fidelity amplification over a wide frequency range. Another benefit is that the ear canal remains open, meaning that sounds not produced by the device can still be heard and the voice of the user sounds natural. There is also potential for the remote transmission of signals to this device, which could be of use in individuals without hearing impairments. 
Hearing enhancement in healthy individuals could be brought about by other arrangements of radio systems, in which sounds are transmitted directly to the ear of the listener. This reduces background noise and reverberation and has multiple potential applications. Immediate applications include the following: in the classroom, with children who have attention disorders; with devices in the home, such as a television; in noisy factories and other working environments, or with the military, to allow communication signals to be received effectively while hearing protection is being worn.

Further in the future, intensive research is being conducted on hair cell regeneration. Damage to the inner and outer hair cells is a common cause of cochlear impairment. Hair cell regeneration occurs naturally in birds after damage, providing an extra impetus for research into how this might be replicated in humans.

\section{Visual enhancement}

In industrialised countries, retinal degeneration is most commonly caused by age-related macular degeneration (AMD), which usually affects individuals over 65 years of age and accounts for approximately $50 \%$ of those registered blind in the UK. Inherited retinal degeneration affects younger patients and can lead to many years spent with disability. Treatments that use recombinant antibodies for the treatment of some forms of AMD show some promise, but are expensive and require regular injections, for example every month. Dr Matteo Rizzi, Postdoctoral Fellow at University College London with Professor Robin Ali FMedSci, told the workshop that a stable, viable and one-off solution is therefore sought. He described three methods by which this might be achieved in future:
- Retinal implants electronically stimulate retinal cells when placed either on or behind the retina. Integration of such implants presents a significant challenge, however, given the complexity of the neuronal network from the retina. In addition, only very low resolution images can currently be generated, for example those that allow identification of a bright object against a dark background. 67

- To date, about 150 different genes associated with retinal dystrophy have been identified. Efficient gene supplementation in the retina, using viral vectors, has been achieved in mouse models and, more recently, in patients. ${ }^{68,69,70}$ In other cases, where supplementing a specific gene is not sufficient, the use of light-sensitive proteins (e.g. channelrhodopsin-2 from algae) may help to restore light responses in retinal cells, including those that are not normally photosensitive. ${ }^{71}$ However, several limitations currently exist for this approach. First, very bright light is required. Secondly, bypassing the normal retina circuitry by stimulating downstream cells will miss important steps in the processing of visual stimuli. More generally, the production of large volumes of clinical-grade viral vectors remains difficult and expensive, and the changes to the connectivity of the degenerating retina present another obstacle.

- Cell replacement represents a promising solution to restoring function after photoreceptor degeneration. It has recently been shown that transplanted rod photoreceptor precursors do integrate in the recipient mouse retina, form synaptic connections with the correct partners and are able to send a signal to downstream

67 Zrenner E, et al. (2010). Subretinal electronic chips allow blind patients to read letters and combine them to words. Proceedings of the Royal Society B 278, 1489-1497.

68 Smith AJ, et al. (2012). Gene supplementation therapy for recessive forms of inherited retinal dystrophies. Gene Therapy 19(2), 154-161.

69 Bainbridge JWB, et al. (2008). Effect of gene therapy on visual function in Leber's congenital amaurosis. The New England Journal of Medicine 358, 2231-2239.

70 Maguire AM, et al. (2008). Safety and efficacy of gene transfer for Leber's congenital amaurosis. The New England Journal of Medicine $\mathbf{3 5 8}$ $2240-2248$

1 Busskamp V, et al. (2010). Genetic reactivation of cone photoreceptors restores visual responses in retinitis pigmentosa. Science $\mathbf{3 2 9}$, 413-417. 
cells, including those in the visual cortex. ${ }^{72,73}$ It is now essential to identify the best source of cells for transplantation and to obtain a sufficiently large amount of cells from it. Researchers currently use retinal cells from donor mice, which is not an option for humans. However, stem cells have shown promise. An entire synthetic human retina has been produced in vitro using embryonic stem cells, and this technique could provide many appropriate cells for transplantation. ${ }^{74}$ In cases such as AMD, it may be sufficient to replace a very small percentage of the cone photoreceptors in the foveola to restore vision; research with rod photoreceptors has suggested that this is a realistic goal.

Participants discussed how these kinds of techniques may in the future aid research into the extension of the range of human vision to include additional wavelengths. Examples exist in animals, such as snakes that can detect infrared wavelengths, which might provide a source of research for developing approaches that can be used in humans. Potential applications could be envisaged in the military, but also in other employment, from night watchmen, safety inspectors, gamekeepers, etc, including the possibility of enhanced vision at night.

\section{Enhancement of mobility and limb function}

Impairments to mobility, coordination and upper limb function are very common, but employment rates for such individuals are well below the national average. ${ }^{75}$ Two of the main disabilities associated with low levels of employment are impairments of the legs or feet and of the arms or hands. Several technologies to enhance mobility are currently on the market, including bionic limbs and exoskeletons. Although design of these technologies is continuously improving, several challenges remain in designing devices that even come close to mimicking the full functionality of human limbs. Dr Laurence Kenney, Reader in Rehabilitation Technologies at the University of Salford, highlighted three key challenges.

\section{Control}

Issues with the control of upper limb prostheses illustrate some of the major challenges common to some other assistive devices, ${ }^{76}$ including the following:

- The signal that controls powered prostheses is the electrical activity measured via socket-located electrodes overlying one or two residual muscles. The transduced signal is influenced by external factors, such as sweat and loads on the socket-located electrodes, which introduce uncertainty into the control system.

- The motor that opens the hand is switched on once the rectified and smoothed signal exceeds a threshold. Such an approach to signal processing is slow, leading to a lag between command and response.

- The absence of feedback on the state of the hand means that the user must rely on visual feedback, a much slower feedback loop than spinal reflexes.

- Most hands operate with one, or at most two, simultaneously controlled degrees of freedom, owing to the limited number of control sites and difficulty with controlling more independent degrees of freedom. This greatly limits their dexterity.

These limitations mean that current devices offer limited enhancement of functionality, which is reflected in low levels of everyday use and high rejection rates. ${ }^{77}$

72 MacLaren RE, et al. (2006). Retinal repair by transplantation of photoreceptor precursors. Nature 444, 203-207.

73 Pearson RA, et al. (2012). Restoration of vision after transplantation of photoreceptors. Nature 485, 99-103.

74 Eiraku M, et al. (2011). Self-organizing optic-cup morphogenesis in three-dimensional culture. Nature 472,51-56.

75 Office for National Statistics (2011). People with disabilities in the labour market - 2011. http://www.ons.gov.uk/ons/dcp171776 242963.pdf

76 Bongers RM, et al. (2012). Hierarchical levels of construction of movements applied to upper-limb prosthetics. Journal of Prosthetics and Orthotics 24,67-76.

77 Biddis E \& Chau T (2007). Upper-limb prosthetics: critical factors in device abandonment. American Journal of Physical Medicine and Rehabilitation 86, 977-987. 
New technologies might in future address these issues. The slow nature of control algorithms may be improved by using different physiological signals such as real-time ultrasound, ${ }^{78}$ brain-computer interfaces ${ }^{79}$ and for above-elbow amputees, targeted muscle re-innervation. ${ }^{80}$ However, with the exception of targeted muscle re-innervation, these technologies remain some way from clinical exploitation. Artificial feedback loops are being explored to reduce the need for visual feedback. These include systems already in clinical use for controlling grip strength based on slip detectors, and the rapidly emerging area of biofeedback to the residual limb. ${ }^{81}$ Finally, more dextrous hands are already in use in anticipation of better control approaches emerging. 82

\section{Energy efficiency}

A good example here comes from studying the gait of lower-limb amputees. Gait consists of a stance phase while the foot is in contact with the ground, and the swing phase while the foot is swinging forward. The energy efficiency of gait is influenced by the positive mechanical work at the ankle in the final part of the stance phase (i.e. at push off). Standard prosthetic feet are passive viscoelastic devices that store energy early in stance, and release it later in stance. However, in contrast to the human ankle, when walking with a passive prosthetic foot there is no positive work produced at the ankle and no control over how the stored energy is released. The combined effects contribute to the low energy efficiency of amputee gait; about $20 \%$ lower in belowknee amputees and worse in above-knee amputees. ${ }^{83}$ Research is looking to address this problem using advanced control techniques. For example, the use of springs and a clutch mechanism can facilitate more effective storage of energy, which can then be retained until near the end of the stance, when it can be used for push off. 84

\section{Usability}

Difficulty in using assistive devices has limited their uptake. A good example is provided by the use of functional electrical stimulation for foot drop, a condition that is common after stroke and is characterised by the foot failing to lift properly during swing, leading to slow, unsteady and tiring gait. The use of small electrical pulses to induce a muscle contraction can help to correct foot drop. Standard devices use two electrodes, the placement of which is critical to good performance. However, it can be challenging for individuals recovering from stroke to remember the correct position of the electrodes and poor placement can lead to the foot turning sideways, or even downwards. Systems to overcome this issue are currently being developed with patients, in which the critical electrode is divided into an array of small electrodes and software is used to locate the best spot for stimulation. ${ }^{85}$

To overcome these challenges and optimise the development of these technologies over the next decade, interdisciplinary approaches and co-development with users will be increasingly valuable. Devices need to become increasingly automated and easy to use.

78 Zheng YP, Chan et al. (2006). Sonomyography: monitoring morphological changes of forearm muscles in actions with the feasibility for the control of powered prosthesis. Medical Engineering and Physics 28(5), 405-415.

Kreilinger A, Neuper C \& Müller-Putz GR (2012). Error potential detection during continuous movement of an artificial arm controlled by brain-computer interface. Medical and Biological Engineering and Computing 50(3), 223-230.

80 Kuiken TA, et al. (2009). Targeted muscle reinnervation for real-time myoelectric control of multifunction artificial arms. Journal of the American Medical Association 301(6), 619-628.

81 Saunders I \& Vijayakumar S (2011). The role of feed-forward and feedback processes for closed-loop prosthesis control. Journal of NeuroEngineering and Rehabilitation. 8, 60.

82 For examples, see http://www.touchbionics.com/ and http://bebionic.com/.

83 Waters RL \& Mulroy S (1999). The energy expenditure of normal and pathologic gait. Gait Posture 9(3), 207-231.

84 Collins SH \& Kuo AD (2010). Recycling energy to restore impaired ankle function during human walking. PLoS ONE 5, e9307.

85 Reeves M, et al. (2010). Shefstim: a clinical trial of self-tuning array stimulation for foot-drop. In Kenney LPJ and Cooper G (eds) (2010). Proceedings of the 1st Annual Conference of the UK and Republic of Ireland Chapter of the International Functional Electrical Stimulation Society. University of Salford, Salford, UK. 


\section{Physiology and tissue engineering}

Research into human physiology and tissue engineering provides numerous opportunities for physical enhancement. Professor Molly Stevens, Professor of Biomedical Materials and Regenerative Medicine at Imperial College London, told the workshop that every organ and tissue in the body is now a target for research. Tissue engineering combines cellular biology, materials science and engineering to generate new tissues. Regenerative medicine is an application of tissue engineering whose success depends on careful consideration of the structure and function of the cells, and the tissue or organ, to be repaired. Many factors can influence success, including the tissue type, the nature of the disease, the size and scale of the tissue defect and the age of the patient. Although this kind of research is not new, the goals of these endeavours have changed in recent years. The ambitious early aims of reconstructing entire organs have largely given way to smaller, more attainable goals. For example, rather than trying to replace an entire heart, clinical advances in cardiac repair now focus on targeting coronary arteries, valves and the myocardium muscle individually.

The use of stem cells to regenerate tissue is an area of significant research activity. There are currently almost 3000 clinical trials globally that use stem cells for numerous applications. ${ }^{86}$ In terms of more complex tissue engineering, potential developments over the next decade are tissue-dependent and, in part, determined by the types of biomaterial available. For example, there are multiple options for work on bone and cartilage, but fewer in more complex tissues such as nerves.

As a result, one of the most advanced applications of tissue engineering is in joint replacement, where the use of stem cells and bioactive scaffolds can generate tissues that are more likely to be successfully integrated into the recipient. Professor Stevens described 'in vivo bioreactor' for bone regeneration which harnesses a patient's own cellular processes to enable new bone tissue to be generated underneath the surface of an existing bone-an area rich in pluripotent cells. This technique provides new bone in sufficient quantities to be transferred elsewhere within the same patient. Because the bone is generated by the body itself, it is biomechanically identical to native bone. ${ }^{87}$ These kinds of techniques are also being explored for application to other vital organs, such as the liver or pancreas.

Many tissue engineering approaches currently require the use of three-dimensional scaffolds in place of an extracellular matrix. Cells are seeded into the scaffolds and new tissue develops. 88 New 'sheet-based' tissue engineering techniques are now in development, which avoid the use of a scaffold, and within the next 10 years we could see 'off-the-shelf' engineered tissues that are entirely specific to the patient. Blood vessels are a likely application here. ${ }^{89}$

Given the prevalence and likely future burden of heart disease, the heart is a particular focus for research. For example, over 20 million individuals worldwide live with congestive heart failure. ${ }^{90}$ Participants noted that where the future of work is concerned, cardiovascular health is important for several reasons, including the importance of cardiorespiratory fitness to both physical and mental wellbeing, and because fitness is a source of stamina, endurance and productivity.

Solutions to heart disease might see patients' cells seeded into a matrix that is placed over the myocardium muscle to restore function, for example after heart attack or in engineering

86 For examples, see http://www.eurostemcell.org

87 Stevens MM, et al. (2005). In vivo engineering of organs: the bone bioreactor. Proceedings of the National Academy of Sciences of the USA 102, $11450-11455$.

88 Langer R \& Vacanti JP (1993). Tissue engineering. Science 260, 920-926.

89 L'Heureux N, McAllister TN \& de la Fuente LM (2007). Tissue-Engineered Blood Vessel for Adult Arterial Revascularization. The New England Journal of Medicine 357, 1451-1453.

90 Redfield MM (2009). Heart failure:an epidemic of uncertain proportions. The New England Journal of Medicine 347(18), 1442-1444. 
replacement valves from a patient's own cells (rather than using mechanical valves or those of animal origin), and these may soon enter clinical trials. Further in the future, techniques might enable development of entirely engineered hearts, in which cells are removed from a heart until only the matrix remains, which is then repopulated with patient-specific cells. Research is also exploring how whole organs might in future be 'printed' using cells and polymers. However, the complexity of the task, for example to arrange blood vessels correctly in a new organ, means we are some years away from clinical application. As progress is made in work on specific parts of tissues and organs, this kind of more complex option may not be necessary.

In severe cases of organ failure, transplantation is used. This, however, is expensive, requires the use of immunosuppressants and is accompanied by some ethical concerns. Options for heart transplant patients have been improved by artificial heart pumps, or ventricular assist devices, particularly to bridge the gap to transplantation. In fact, heart pumps are now performing almost as well as transplants in terms of survival rates. ${ }^{91}$ Research is also exploring how heart pumps might be interrelated with stemcell work to improve the effectiveness of heart transplants further. Professor Stephen Westaby, Cardiac Surgeon at John Radcliffe Hospital in Oxford, told the workshop that this kind of artificial heart has already been used in trials and could begin to replace transplantation within the next decade. ${ }^{92}$ However, such solutions are currently very expensive, up to $£ 100,000$, and more inexpensive designs will be needed if they are to become accessible to healthcare systems.

Developments are also needed to optimise the power supply to these devices, which require a permanent power line from outside the body into the internal organ. Such a set-up brings vulnerability to infection. Techniques to fix the power line in place, using a pedestal planted in the skull, could help to reduce this issue. Professor Westaby also reported that artificial lungs are in development, but that these present further challenges as recipients must carry gas, as well as a power supply. ${ }^{93}$ Implantable kidneys and liver could also be on the horizon.

\section{Nutrition and performance enhancement}

A healthy lifestyle, including good diet and nutrition, is clearly fundamental to maintaining health and wellbeing. Specific nutritional approaches might be used to improve particular aspects of performance, however. Participants discussed how these are often most useful to individuals working at the limits of human capacity. Due to the illegality of performanceenhancing drugs and the capacity to exhaust options to improve performance through training, sport is one of the first areas to embrace new developments in nutritional interventions that might provide users with a small but significant competitive advantage. Professor Ron Maughan, Professor of Sport and Exercise Nutrition at Loughborough University, told the workshop that athletes are often willing to try new approaches even if some aspects of efficacy and safety are unknown. It may be that these approaches have applications in specific cases in the wider population as well.

Long-term nutritional approaches can facilitate improved performance, for example enabling harder training without chronic fatigue, injury and impaired immune function. Training regimens can be designed to enable muscle remodelling and to alter gene expression, and the right nutrient environment can enhance the functional consequences of a training

$93 \mathrm{Wu} \mathrm{ZJ,} \mathrm{et} \mathrm{al.} \mathrm{(2012).} \mathrm{Thirty-day} \mathrm{in} \mathrm{vivo} \mathrm{performance} \mathrm{of} \mathrm{a} \mathrm{wearable} \mathrm{artificial} \mathrm{pump-lung} \mathrm{for} \mathrm{ambulatory} \mathrm{respiratory} \mathrm{support.} \mathrm{The} \mathrm{Annals} \mathrm{of}$ Thoracic Surgery $93,274-281$. 
programme. For example, intake of essential amino acids (especially leucine, which can be in the form of whole proteins from food rather than as supplements) after exercise promotes muscle protein synthesis and net protein balance, and enhances muscle adaptation. ${ }^{94}$ Such approaches could be applied to elderly or unwell individuals with disuse atrophy, i.e. where muscle mass decreases and the muscle weakens owing to age or lack of use. Muscle has been shown to be responsive to training and nutritional interventions even into extreme old age. ${ }^{95} \mathrm{~A}$ recent study showed that maintaining amino-acid availability by intragastric infusion of protein during the night increased net protein synthesis in elderly men. ${ }^{96}$ Some nutritional supplements also show promise in supporting muscle growth, fat loss and physical performance. Dietary nitrate (found in high concentrations in beetroot and some other vegetables), for example, can reduce the oxygen cost of exercise by $3-4 \%$, apparently by improving mitochondrial efficiency. ${ }^{97}$ Such an effect could have significant benefits for endurance athletes, but could also benefit individuals with pulmonary or cardiovascular impairments that limit oxygen delivery to peripheral tissues. There is emerging evidence also for a role for dietary nitrate in blood pressure reduction and other cardiovascular and metabolic benefits. ${ }^{98}$

Nutrition may also be used acutely to provide specific performance effects. Caffeine is an obvious example here, which can enhance exercise performance by actions on adenosine receptors in the central nervous system.

Carbohydrate intake can enhance performance by slowing the development of fatigue during activity lasting more than one hour. Although there is a physiological explanation for this effect (the sparing of endogenous glycogen stores), there is also a psychological aspect, in terms of the perception of effort required, which can often be the ultimate limit to performance. For example, in studies where a carbohydrate solution is swilled around the mouth and not swallowed, some improvement in performance is seen, though not as much as if it is swallowed. ${ }^{99}$ It is not yet clear whether the brain adapts after multiple experiences. The brain is increasingly a target for studies into overcoming fatigue, and brain imaging and pharmacological interventions are now being used to explore the neurological and neurochemical bases for these effects. This could lead to novel approaches to performance enhancement, both for athletes and for other populations.

\section{Cosmetic enhancement}

Although cosmetic enhancement was not a central focus of the workshop, participants highlighted that it is one of the most wellestablished types of physical enhancement, which has applications that are both restorative or that take individuals 'beyond the norm'. Techniques that enable cosmetic enhancement are constantly evolving, with new ones being developed and the range of different enhancements possible widening. It will become increasingly difficult to distinguish cosmetic enhancement from more traditional beauty treatments, for example as beauty products and treatments become increasingly sophisticated. Cosmetic enhancement could have particular relevance to the context of work as the appearance of being younger may have implications for one's employment prospects, which might be particularly

94 van Loon LJC \& Gibala MJ (2012). Dietary protein to support muscle hypertrophy. In Maughan RJ and Burke LM, eds. (2012) Sports nutrition: more than just calories - triggers for adaptation. Nestlé Nutrition Institute Workshop Series, 69, pp 79-95. Karger, Basel.

95 Breen L \& Phillips SM (2011). Skeletal muscle protein metabolism in the elderly: Interventions to counteract the 'anabolic resistance' of ageing. Nutrition and Metabolism 8, 68.

96 Groen BB, et al. (2012). Intragastric protein administration stimulates overnight muscle protein synthesis in elderly men. American Journal of Physiology, Endocrinology and Metabolism 302(1), E52-E60.

97 Larsen FJ, et al. (2011). Dietary inorganic nitrate improves mitochondrial efficiency in humans. Cell Metabolism 13(2), $149-159$.

98 Lundberg JO, et al. (2011). Roles of dietary inorganic nitrate in cardiovascular health and disease. Cardiovascular Research 89(3), 525-532.

99 Carter JM, Jeukendrup AE \& Jones DA (2004). The effect of carbohydrate mouth rinse on 1-h cycle time trial performance. Medicine and Science in Sports and Exercise 36(12), 2107-2111. 
pertinent within an ageing society. However, it is also possible that as an increasing proportion of the workforce is of older age, any real or perceived need to exhibit a youthful appearance for reasons related to work will decline. The relevance of cosmetic enhancement will inevitably vary with different types of job.

The use of pharmaceuticals is also relevant here. The use of anabolic steroids for the purposes of bodybuilding and image enhancement is rising among the general public and young people in particular. ${ }^{100}$ In 2010, the Advisory Council on the Misuse of Drugs (ACMD) expressed concerns about the use of anabolic steroids, which are currently classified as class $C$ drugs by the UK Misuse of Drugs Act. As well as enabling image enhancement, these drugs can also improve strength, which could be an attractive outcome to individuals (or employers) working, for example, in manual labour industries. Some of the harms of these drugs are discussed in Chapter 5. 


\section{Commercialisation opportunities and challenges}

\section{Overview}

Whether or not enhancement technologies represent a viable investment opportunity will clearly determine the level of development seen. This market might represent a profitable new industry but defining the timing of market realisation is challenging in view of technical, regulatory and collaborative challenges. Non-invasive technologies are likely to attract more investment, given the lower level of regulation and because provision is less likely to rely on finite state resources. Such technologies, especially if they exist online, could have enormous reach. Markets are global as demonstrated by the advent of social media; sometimes beyond the regulation and control of governments across the world. Balance needs to be struck between promoting and over-claiming the benefits of new technologies.

There are also questions to be addressed as to whether the development of enhancement technologies could represent a good target for UK investment and whether the UK should seize on the opportunity to create a new industry, or enhance existing domestic industries and their workforces to compete successfully in a shifting global market.

The discussion at the workshop focused less on how enhancement use among employees might benefit the competitiveness of an organisation, which is explored further in Chapter 5 .

Technologies can only reach the market if they have sufficient financial backing. Participants discussed how several determinants influence the commercialisation opportunities of a novel technology, such as whether it represents unique intellectual property and the size of the market, but the key issues relate to the market risk (technology adoption) and potential uptake, and the risk of the technology failing to deliver its claimed cost-benefit advantages. When considering enhancements in the context of work, technological development must consider the end users - both employers and employees - and the views of particular interest groups such as trade unions.

The enhancement technologies discussed probably represent multiple markets, rather than a single 'enhancement' market. Dr Andrew Elder, Partner at venture capital investor Albion Ventures, reminded the workshop that investment decisions, at least for private investors, are based not only on commercial opportunities (market prospects), but on the investment prospects, i.e. investors must envisage returns within a set period. Dr Elder noted that some enhancement technologies could represent huge commercial opportunities, in both healthcare and non-healthcare markets.

In healthcare markets, technologies are often designed to correct some kind of 'deficit', as is the case with several of the physical enhancements described. The potential size or attractiveness of healthcare markets is often limited by several constraints, including a high degree of regulation and a lengthy route to market. The existence of such constraints varies, however. Traditionally, medical devices are subject to less scrutiny than drugs, although recent cases in which approved devices led to significant side effects will serve to increase the regulatory requirements on new devices. The INFUSE $®$ bone graft, for example, was approved by the US Food and Drug Administration for lower back procedures, but the high concentration of growth factor implanted in this device led to side effects including cancer and male sterility. ${ }^{101}$ 
We see a different investment dynamic with the non-healthcare market, which might represent big commercial and investment opportunities as it is not subject to the same constraints. Some of the non-pharmacological cognitive enhancements could be attractive to investors here. Enhancement tools that exist online, for example, bring enormous potential reach for lower relative investment. Cognitive training games could provide a high margin as they can be widely distributed at low cost and bring minimal downsides such as side effects.

Whether an enhancement can create a market depends on its target indication, for example in terms of the level of enhancement produced, the degree of unmet need and the severity of the underlying deficit being addressed. Investment decisions are founded on understanding market needs and gaps for the creation of new market categories; it is vital to assess whether the nature of the enhancement is to push or be pulled into the market.

The pricing structure of the market also has a huge impact on market opportunity: pricing and who pays are key determinants of commercialisation opportunities. A large component of costs in the healthcare market is covered by healthcare systems, which has huge implications for the commercial viability of an opportunity. Hearing aids have been commercially attractive because they have a high margin and can be produced in high volumes, with relatively low regulatory hurdles; there is a very identifiable end-user, there are large numbers of end-users (with an increasingly aged population), the benefits are demonstrable through the extended 'independence' of the end-user and they are accessible to healthcare systems in cost terms. Exoskeletons; potentially used by manual workers as well as the elderly, on the other hand, must be adapted to the user, making production difficult to scale-up. They also require a much greater service element to support integration and training. As a result, without reductions in costs, high technology exoskeletons are currently unlikely to be widely affordable to employers and healthcare systems in the foreseeable future, though they may attract self-pay customers who are better positioned to assess their degree of enhancement and so the price they are prepared to pay for it.

Mr Phil Newman, Chief Executive Officer of PERGALI, who previously led commercial development and marketing at Touch Bionics, a provider of prosthetic technologies, told the workshop that the only way to assess and respond to the opportunities accurately, as well as the challenges, is to bring these factors together to create a market map of potential physical and cognitive enhancements; and identify each one's proximity to realisation. Although this represents considerable work, it would aid the identification of commercial opportunities and help nearer-term prospects to appear more tangible to the audience (both consumer and investor). Technologies would be ranked and rated based on a selection of factors, such as the following:

- $\quad$ Time to market (proximity of available technology).

- Regulatory considerations.

- Cost of development and therefore market price.

- Target users and application of the technology.

- Return on investment and health economics.

Such a map can help marketeers to make more informed decisions about new technologies and can drive investment decisions, which will also be supported by developing a good understanding of potential markets, including what users might want from technologies and how technologies might be integrated into their future lives. Mr Paul Mason, Head of Development at the Technology Strategy Board, stressed that markets are global and thus defined by the actions of multiple governments. Any market map should address the international market. The foundation for investment decisions, as well as those 
related to use, regulation and accessibility of technologies, must be an understanding of global developments. Although this will be an important component of informing UK competitiveness, it remains important to work with other countries to inform this awareness.

Professor Nikolas Rose, Professor of Sociology and Head of the Department of Social Science, Health \& Medicine at King's College London, cautioned that 'over claiming' the benefits of technologies can impact on the future success of novel developments. Disciplines such as genomics, neuroscience and synthetic biology provide many interesting insights and may bring benefits to users, but there is a need to distinguish the market hype from reality. Professor Rose told the workshop that 'over claim' characterises emerging technologies and is linked to a 'political economy of hope', in which the hopes of patients, politicians, scientists and commercial enterprises sit alongside warnings from the military that we may see a new arms race in enhancement technologies, to drive the discourse of enhancement. Professor Rose cautioned that this language, including the term 'enhancement' itself, is embedded in this pervasive culture of 'over claim'. Caution and scepticism support robust science and facilitate more productive discussion. If overestimated promises do not come to fruition, there are negative implications for industry, science and users. Another participant stressed that although scepticism can be helpful, being over-cautious can slow progress and delay access to technologies that could help numerous individuals. 


\section{Potential implications for the future of work}

\section{Overview}

Enhancements could have many applications to work in the future, which might benefit both employees and employers, but the potential implications may well be complex, unpredictable or divisive.

- Enhancement could benefit employee efficiency and even work-life balance, but there is a risk that it will be seen as a solution to increasingly challenging working conditions, which could have implications for employee wellbeing.

- Work to identify the potential harms of new technologies should be pursued to support decisions by users - both employees and employers - but data are currently lacking and difficult to collect.

- The usefulness of technologies will vary with context. Enhancements will benefit different occupations in different ways and, importantly, every user will exist in unique circumstances. To benefit fully from enhancement technologies, integration must therefore focus on the individual.

- There are few data on the current and potential use of enhancements or on how publics view the use of enhancements at work. Ongoing dialogue will be vital in developing an understanding in these areas.

- Particularly complex questions are raised by the use of enhancements in occupations where work is related to responsibilities to others, for example surgeons performing lengthy operations or passenger coach drivers.

- The use of enhancements could widen access to certain occupations. However, access to the enhancements themselves may be restricted by cost, thus raising questions over who funds provision.

- If technologies enter mainstream use at work, there is a risk that individuals will feel coerced into using them, with consequences for individual freedom.

- The use of restorative technologies could enable disabled individuals to enter, or return to, work and might lead to a blurring of the boundary between those considered disabled and those not. This could have significant implications for individuals who do not wish to make use of such technologies and for any decisions over funding that are related to whether a technology is defined as enhancement or restoration.

Although there has been extensive discussion of the general implications of human enhancement, as far as we are aware there has been little debate about how human enhancement technologies might impact on the future of work. This chapter looks at how enhancement might be used at work, considers the data required to enable a full understanding and explores how issues raised in general discussion about enhancement might be of particular relevance to this context and whether any unique issues arise. Any such issues could influence the desirability, acceptability and future use of enhancements at work. 


\section{Enhancement and work}

Enhancements will not simply be applied to all individuals and all organisations; their expense and the likelihood of diverse effects in different individuals are just two possible reasons for differential uptake. To use enhancements most effectively (or any other technology or training method), any factors limiting performance must be identified and targeted. The use of enhancements is thus likely to be task-specific and designed to meet the user's needs. In practice, of course, the use of enhancements will not be as simple as identifying the limiting factor and applying a particular technology to improve it, and participants discussed how the use of technology alone can only ever form part of an approach. Many other factors, including opportunity and commitment to the cause, will influence the outcome of an individual's efforts. However, enhancement could play a role in work, by the following means:

- Influencing an individual's ability to learn the tasks required for their work.

- Influencing their ability to perform those tasks.

- Influencing their ability to enter a profession.

- Influencing their level of motivation when performing tasks.

- Reducing work-related damage or stress physical and cognitive.

- $\quad$ Supporting individuals to return to work after illness.

Thus enhancements will likely impact on different occupations in different ways. Where work is strongly based on competition, such as in the case of athletes, there will be a strong motivation to enhance. This is demonstrated by, for example, this group's position at the forefront of exploring nutritional supplements as enhancements. Individuals involved in work that is high risk or high stress may benefit from enhancements if they improve safety and reduce potential harms. This might include the desire to diminish certain experiences or abilities, for example the effects of jetlag or of the neurological condition synaesthesia, in which two or more of the human senses are involuntarily joined together. However, as discussed in relation to using technologies in practice below, this is accompanied by the risk that enhancements might be seen as a substitute for a healthy working environment and conditions. Similarly, shift workers could benefit from enhancements that improve their awareness or resilience to cope with challenging working patterns, which can be associated with mental or physical problems. Equally, occupations that require particular patterns of focus could benefit from enhancements that facilitate achieving such patterns. For example, surgeons may need to be able to concentrate for extended periods, whereas other jobs such as air traffic control can require very rapid reactions during periods of relative uniformity. ${ }^{102}$ As an extrapolation to this, it is possible that in these high-responsibility occupations enhancement could be seen as a moral obligation, or even demanded by the public. Recent examples of traffic accidents involving passenger coaches draw attention to the drivers of these vehicles as another potential target for such demands. Situations like this will require careful consideration.

Enhancing individuals could also be of benefit to collectives. Organisations may see improvements in, for example, employee efficiency and coordination, and thus also in productivity. There could be economic benefits to organisations and society more widely as a result of a minor but widespread improvement in cognition. In addition, as discussed in Chapter 2, technology could enable us to use collective intelligence to solve problems that were beyond the capabilities of previous collectives. 


\section{Using technologies in practice}

The nature of work, of work-associated illnesses and of the composition of the workforce is likely to change over the next decade and beyond (see Box 2). There could be real opportunities for enhancement technologies to be used to the benefit of employees, attractive both to them and their employers. Enhancers might support individuals in adapting to the changing work environment, for example by supporting older people to continue to work. They could also enable more efficient working and thus could facilitate an improvement in work-life balance and employee wellbeing. In addition, businesses are likely to experience rising pressure to gain a competitive edge, given the ongoing global economic situation and continued rise in the globalisation of workthis could encourage an 'enhancement race'. Using enhancements will need to represent a financially viable option; for example, the cost of any increase in productivity should be less than simply employing extra staff. Also relevant here is the fact that it may be cheaper to employ able-bodied people rather than to buy complex technologies to enhance the less able.

For technologies to support individuals successfully in continuing to work, there must be a realistic assessment of genuine needs and of what technologies can deliver. The user's expectations must coincide with the potential and actual outcomes; incompatibility between the two can result in discontinuance of use and disenchantment. Not only this, but employers must understand where there are discrepancies between needs and outcomes if they are to place realistic expectations on their employees and support those employees in making the best use of technologies. In practice, it will be important to consider what the most appropriate intervention is for any individual, in terms of the objectives of enhancement. This will depend on the nature of the work in question.

Participants noted that, in the next few decades, we are unlikely to see enhancement technologies that provide any more than a relatively low degree of improvement in a particular capacity for a finite amount of time. The complexity of the brain, for example, and the sociotechnical system within which it functions, means that we cannot currently know for sure that when we try to modify one particular faculty, all others will remain unchanged. Studies into cognitive enhancement do not normally also investigate whether there is a cost to enhancement. If a decline in other functions results, it will be important to understand how and to what degree this might be an issue. This kind of information will be important to individuals, who will have unique objectives for their use of enhancements and will draw different conclusions about riskbenefit ratios. One participant highlighted the perspective from evolutionary biology; evolution has seen the optimisation of processes through biological trade-offs and we must understand this to identify where we might feasibly improve capabilities.

\section{Dr Pamela Gallagher, Senior Lecturer in} Psychology at Dublin City University, stressed that we must understand an individual's psychosocial perspective; that is the personal, social, emotional, cultural and environmental circumstances that will enable users to benefit most from a technology. An enhancement technology, irrespective of whether it is placed in the user's environment, on their person or in their body, is effectively an interface between that individual and the life they wish to lead. It is therefore how people react to technology, rather than the technology itself, that determines how enhancing it will be. Box 4 outlines the importance of a usercentred approach and of the role that reinforcement and feedback play in an individual accepting a technology. 


\section{Box 4 Aspects of a psychosocial perspective}

\section{A user-centred approach}

Enhancement technologies, even those that represent collective enhancement, are ultimately used by individuals. Integration therefore depends on human behaviour. Psychological and social aspects must be combined to promote a user-centred approach to the use of novel technologies. Successful uptake may be improved by drawing on, for example, models of human behaviour, motivation theories, self regulatory theory and goal theory. Efforts to generate a model for matching person with technology take into account not only the salient characteristics of a technology, but also the characteristics of the environment and the circumstances in which it will be used, including relevant features of a user's personality, temperament and preferences. ${ }^{103}$ Such models can help us to understand how employees and employers, as end users, might make best use of technologies. For example, an individual with a prosthesis could view themselves in relation to that device in several ways. For some, the prosthesis may represent their inability to perform certain activities, emphasise their lack of completeness or be a focus for perceived stigma associated with their physical condition. Yet, for others, a prosthetic device may represent their enablement or their ability to harness technology and to participate fully in society. Realising the potential of a new enhancement technology may be restricted by our ability to integrate it into our lives, and how people 'read' the technology they are using is potentially one of the most powerful psychosocial factors in its integration. Every user has unique circumstances and the intended use must match the user, even for technologies that are likely to be widely used.

It takes time to adapt to using a new technology. Positive and effective interventions may require significant effort, time and labour on the part of the user, which may result in a period of time during which they are less, rather than more, efficient and productive. In some cases, the desired change will never arrive, which, given that the technologies are meant to provide improvement, could be perceived as a 'failure' of the individual. The user must therefore also be central to evaluating the outcome of a technology, which must recognise that there is a limit to what can be achieved and avoid preconceived ideas about what might be important to the user. Benchmarks of success should be flexible, achievable and focused on the user. Success is defined not only in terms of realising the primary objective of a technology, but on the psychological, spiritual, emotional and social components that contribute to the person's quality of life, which will again vary between individuals.

\section{Reinforcement and acceptance of technology}

Feedback can play a critical role in reinforcing the usefulness of technology and is thus fundamental to its successful and continued use. This feedback could come in several forms: from as simple as enjoyment and interest, which in turn may act as an internal motivation for continued use, to the knowledge that one has control over the outcome and function of the technology. Feedback can also inform improved use of a technology, through monitoring progress and comparing current achievements to the ultimate goal. Setting achievable goals and sub-goals is crucial, and sometimes regaining functionality will be a slow and arduous process, meaning that immediate reinforcement is not possible. Such cases must be recognised so that interim motivations and rewards can be identified. 


\section{Social influences}

We must also acknowledge the impact that a technology will have on others and the role this will play in its integration. Successful integration of technology into work or lifestyle does not only depend on the user, but on the acceptance of the technology by members of their immediate social or work network. Public acceptance of technologies is one of the most significant challenges to their translation into everyday practice. For example, if some students use cognitive enhancers to aid examination performance, this will impact on their peers, who may not see the practice as acceptable.

Generally participants felt that if we use technologies to address any of these issues, we must tread carefully. Enabling individuals to work more comfortably is desirable.

However, as highlighted by Professor Rose, it is very different from using technology to try to transform workers, whether young or old, to fit into an increasingly demanding and 'intolerable' work regime. For example, individuals might be able to cope with the increasing globalisation of work by making use of modafinil to overcome jetlag. However, other technologies will enable greater use of video conferencing, for example, which could enable working conditions to be changed, rather than the employee. Making work more technological in this way emphasises the position of humans as 'components' of a system, and careful consideration is needed as to whether this is acceptable, and whether instead we should be looking to 'humanise' work. Good job design aims to provide employees with an appropriate range of activities and interactions in their work, in which stress and intellectual demands are appropriately balanced and employees are granted adequate levels of control over their work. Such job design aims to provide not only job satisfaction, but circumstances in which employees are sufficiently alert so that they can respond when necessary. For example, jobs that require fast responses, such as air traffic controllers, include plenty of breaks to maintain their concentration. Concentration aids may allow them to work better for longer, but a system that relies on enhancement technologies may result in jobs that are generally less satisfying and, further, could introduce additional failure mechanisms, where employees no longer respond to situations as required. Moreover, there are likely to be long-term risks to health and wellbeing of prolonged exposure to demanding working conditions. Furthermore, evidence from studies with shift workers indicates that where they are involved in decisions about how shifts are organised, they are more likely to accept the requirements. ${ }^{104}$ It may be that simply involving individuals in decisions about the use of technology improves the likelihood of it being integrated as intended.

\section{Understanding potential harms}

Although enhancements may benefit individuals or organisations, this must be balanced against potential harms, some of which we can predict. For example, the ACMD has drawn attention to the potential harms of using anabolic steroids for non-medical purposes on multiple occasions over the past few years. These drugs have multiple physiological effects, most notably anabolic effects (such as skeletal muscle and bone growth) and androgenic effects (such as stimulating the development of the male reproductive system and sexual characteristics). As a result, they are associated with a range of potential harms, including acne, cardiovascular symptoms, psychological dysfunction (e.g. aggression) and hepatic dysfunction. Concerns relate particularly to young people because the use 
of anabolic steroids can potentially disrupt the normal pattern of growth and behavioural maturation. Where technology is concerned, the risk of malfunction is clearly a concern. For example, if an exoskeleton is used in the workplace to aid heavy lifting, a malfunction during operation could cause significant danger to the user and to those around them. Vulnerability to computer viruses may also be a risk that needs to be explored further for some of the enhancements discussed, particularly where implanted devices become increasingly sophisticated to the level of simple computers.

There are also less predictable risks of which we are not specifically aware, but can acknowledge may exist. Long-term studies exploring the use of cognitive enhancers in healthy individuals do not currently exist, for example, and it is very difficult to collect data on side effects where technologies are used in more recreational settings.

The increase in online pharmacies means that more individuals are sourcing prescription pharmaceuticals from potentially unregulated sources, which could be out of date, substandard or counterfeit. They will also be supplied without appropriate medical advice, meaning that potential drug interactions will not be assessed and advice will not be given, or monitoring performed, to ensure correct use. Incorrect use could lead to problems: for example, the action of methylphenidate (used in the treatment of ADHD) on the dopaminergic system brings the risk of addiction if it is taken improperly or in high doses.

A poll performed by the journal Nature, to explore readers' use of cognition enhancers, found that one-third of the drugs being used for non-medical purposes were purchased online. ${ }^{105}$ There is also an increase in the prescription of such drugs. ${ }^{106}$ This is partly linked to the medicalisation of human conditions previously not categorised as medical problems. We are seeing a steady increase in prescription rates for stimulants and an increased range of circumstances under which individuals can gain a prescription from a doctor. ${ }^{107}$ For example, modafinil is approved for treatment of shift work disorder in the USA, but clearly the definition of shift work could encompass many different work patterns. ${ }^{108}$ Although these drugs may bring benefits to users, with and without illness, the long-term side effects of such drugs, and in fact most human enhancement technologies, in healthy individuals are unknown. These effects may be different for young people whose brains are still developing. If healthy individuals, young or old, are going to use these drugs, long-term studies are desirable. Such studies present obvious ethical questions and it is thus difficult to gain approval.

There is also a future risk that individuals could inadvertently become 'over-enhanced'. ${ }^{109}$ For example, if cognitive enhancers improve memory too much, people could lose their natural ability to suppress unwanted memories. Alternatively, if many individuals use the same enhancers, we run the risk of becoming a homogeneous society that does not benefit from diversity. On the other hand, enhancements may enable greater diversity in some occupations, as discussed below in relation to equity and fairness.

Much of the science in this area is still experimental or speculative, making it hard to provide accurate risk-benefit assessments on which reliable judgements can be based. Flexibility, continuous monitoring and the opportunity for re-assessment of any decisions is, therefore, vital.

105 Maher B (2008). Poll results: look who's doping. Nature 452, 674-675.

106 Parliamentary Office of Science and Technology (2007). Better brains. http://www.parliament.uk/briefing-papers/POST-PN-285.pdf 107 Ibid.

107 Ibid. 100 and Drug Administration (2010). Medication guide: Provigil. http://www.accessdata.fda.gov/drugsatfda docs/label/2010/020717s030s 034s036MedGuide.pdf

109 Greely H (2008). Towards responsible use of cognitive-enhancing drugs by the healthy. Nature 456, 702-705. 
In addition, discussions are needed around the extent to which the use of enhancements is a decision for the employer, the employee or both. This is discussed further in relation to regulation and policy in Chapter 6 . Potential harms will need to be a key consideration in determining the most appropriate regulatory approach.

\section{Understanding the issue}

In many cases it is difficult to understand how enhancers are, or might in future be, used in practice, particularly for applications to take individuals 'beyond the norm'. The ACMD reported that it is currently very difficult to determine how many people make use of anabolic steroids for non-medical purposes. ${ }^{110}$ Much of the research into cognitive enhancers has been conducted in highly mobile groups, such as senior academics, or groups that require short, intense bouts of concentration, such as students sitting examinations, and even studies within these populations yield mixed results. The extent to which such research represents the wider working population is unclear.

Dr Ilina Singh, Reader in Bioethics and Society at the London School of Economics and Political Science, described the preliminary findings of the UK Smart Drugs Study. ${ }^{111}$ The project investigates students' attitudes and experiences in relation to smart drugs and cognitive enhancement, with the aim of collecting empirical data about the prevalence and practices on university campuses.

The project is currently in its early stages, but initial student focus groups suggest that most students have no personal experience with smart drugs; they do not perceive caffeine to be a smart drug, cannot name any cognitive enhancers except Ritalin (methylphenidate) and are sceptical about the efficacy of smart drugs.
The reasons for this are still under investigation and further data are being sought by way of a national survey. However, this highlights the uncertainty around the use of enhancement technologies in practice. Perhaps it is only within the most competitive student environments that cognitive enhancers are attractive.

To evaluate how enhancement technologies might impact on individuals' lives, there is a clear need to assess levels of awareness and use accurately. Such an assessment does not currently exist, either within the population at large or in the context of work more specifically. ${ }^{112}$

Analysis of use must be supported by an understanding of the factors that might influence public perception of novel technologies. Dr Singh told the workshop that the interdisciplinary approach of empirical bioethics can inform such analysis. It brings together philosophical and empirical fields to improve the practical relevance of moral evaluations. Thus, we can identify broad questions that we must understand if we are to mobilise and enable individuals to assess their own views on novel technologies. This might include the following:

- The ethical concerns that arise from novel technologies.

- How individuals view these concerns.

- How individuals treat these concerns in their everyday lives, for example when there is a conflict with underlying values.

- The social drivers that impact on integration of novel technologies in society.

- The role of government and regulatory processes in enabling individuals to resp ond appropriately, for example by making informed choices.

- The impact of the use of novel technologies on society.

110 Advisory Council on the Misuse of Drugs (2010). Consideration of the anabolic steroids. http://webarchive.nationalarchives.gov.uk/+ http://www.homeoffice.gov.uk/publications/alcohol-drugs/drugs/acmd1/ anabolic-steroids-report/anabolic-steroids?view=Binary

111 anabolic-steroids-report/anabolic-steroids?view=Binary

112 Ragan CI, Bard I \& Singh I, on behalf of the Independent Scientific Committee on Drugs (in press). What should we do about student use of cognitive enhancers? An analysis of current evidence. Neuropharmacology, http://dx.doi.org/10.1016/j. neuropharm.2012.06.016 
Of course, there are two potential levels of acceptance that need to be considered: accepting the concept of enhancement in general and then making decisions about specific enhancement technologies.

For example, willingness to enhance is likely to be related to how fundamental a particular trait is perceived to be to one's sense of self; emotions and traits such as kindness are seen as more fundamental and thus less of an acceptable target to enhance.

We need to evaluate the kinds of attitude that exist and how attitudes and motivations differ among different groups. We must try to understand how the various enhancements are designed to be used, for example specific practical questions such as when, how, in what combinations and the potential long-term consequences. There is currently a lack of fora for education, engagement and debate, but it is very likely that awareness of these technologies will rise, particularly given that media interest in the subject is increasing.

\section{Fairness, coercion and disability}

\section{Fairness and equity}

Enhancement could enable more people to work at their full biological capacity and to meet the necessary entry requirements for an occupation, which could result in a rise in standards or potentially greater opportunity and diversity at work. Individuals with lower cognitive abilities tend to have less choice of occupations, but enhancement may enable them to compete and thus have greater choice. For example, where an occupation requires excellent memory to qualify and practice, enhancements that improve this faculty could facilitate increased diversity within that profession as it becomes more accessible. Of course, this is dependent on how different enhancements affect different people and on an individual's ability to access new technologies.
Participants highlighted that one of the biggest questions relating to the use of human enhancement technologies is that of who funds their provision. Enhancement technologies, particularly in the case of many physical enhancements, are expensive and are likely to remain so. If they are available to buy and are not subject to state support, those with more money will be able to purchase a greater number and sophistication of enhancements. If those technologies enable better performance, they will further the advantage of those people and increase the social division between those who have access via financial resources and those who do not. The competitive nature of work means that this could have significant consequences for the employment prospects of those less able to self-fund enhancement.

Where technologies are seen as health interventions, in countries such as the UK, citizens may expect provision through the National Health Service. However, changing demographics, the ongoing economic recovery and the widening range of available healthcare technologies all remind us that any health system, the UK's included, is subject to a finite budget. Such a budget will not stretch to providing all technologies to all individuals. Added complexity is also driven by the medicalisation of human conditions and the rising use of prescription drugs from other sources, which will blur the boundary between what was previously seen as medical need and what is in fact enhancement of the healthy. This, of course, raises questions that relate to state provision.

\section{Coercion and freedom}

One of the key issues raised in relation to enhancement technologies is the potential for social pressure to lead individuals to be 'coerced' into using enhancers. ${ }^{113}$ This applies particularly to work as it is an inherently competitive activity; both at an organisational level, for example where companies compete 
for business or to achieve a particular goal; and at the level of the employee, for example where the application process for a job is intrinsically competitive.

At an individual level, we have already discussed how awareness of enhancement technologies may currently be limited to particular populations. This in itself may be disadvantageous to others. In addition, if an individual's peers are enhancing themselves in some way, people who do not want to use enhancers for whatever reason could be coerced into doing so, with implications for individual freedom. An online poll in the journal Nature into the use of cognition-enhancing drugs found that $86 \%$ of respondents thought that healthy children under the age of 16 should be restricted from using them, but 33\% of respondents said they would feel pressured to give cognitive-enhancing drugs to their children if other children at school were taking them. ${ }^{114}$ A national programme of public engagement commissioned by the Academy of Medical Sciences in 2007, with support from the Government's Sciencewise programme, revealed concerns that the use of cognitive enhancers by healthy adults would exacerbate an already over-competitive culture. ${ }^{115}$

Participants discussed how pressure might also be felt from employers, both implicitly and explicitly. Economics and globalisation are currently driving up competitiveness. In particularly target-driven atmospheres that look to maximise productivity, an employer could require employees to use enhancers (unless prohibited by regulation). Even if this is not explicitly the case, if expectations placed on employees are based on the performance of those using enhancers, then employee choice will be compromised. For example, expectations on lorry drivers could in future be based on the number of hours for which their awareness levels are sufficient with the use of a cognitive enhancer. Or individuals in labourintensive jobs, perhaps baggage handlers or construction workers, could be required to do work that would be much more easily performed with enhanced strength. This again relates to the potential danger of using enhancement technologies to compensate for increasingly intolerable working environments. Another source of pressure could be the development of technology itself. Individuals may in future feel the need to enhance themselves to cope with enhanced technology, and if this technology is used in the workplace, this pressure will only intensify. The potential role of regulation in such circumstances is discussed further in Chapter 6.

\section{Disability and normality}

Employment rates among individuals with a disability that limits their daily activities (known as DDA disabled) are significantly below the national average for those without a disability. ${ }^{116}$ Therefore, when considering implications for the future of work, enabling disabled people to enter, or continue to participate, in the workforce is clearly an important potential outcome of many of the technologies discussed. In addition, disabilities, for example in hearing or mobility, become more prevalent in older individuals and such people will increasingly remain in work in the future.

The workshop considered technologies that are both restorative or can take individuals 'beyond the norm', a distinction that Dr Jackie Leach Scully, Reader in Social Ethics and Bioethics and Co-Director of the Policy Ethics and Life Sciences Research Centre at Newcastle University, reported could have beneficial outcomes. Previously, regulatory decisions were considered in terms of defining what was (and was not) permissible in terms of therapy and enhancement. Such a distinction requires a definition of 'normality', which

114 Maher B. (2008). Poll results: look who's doping. Nature 452, 674-675.

115 Academy of Medical Sciences (2007). drugsfutures: public engagement on the future of brain science, addiction and drugs. Academy of Medical Sciences. London. http://www.acmedsci.ac.uk/p48prid47.html

116 Office for National Statistics (2011). People with disabilities in the labour market - 2011 http://www.ons.gov.uk/ons/dcp171776_242963.pdf 
Dr Scully reported was not only difficult, but also unethical. Referring to enhancement in general destabilises the idea of there being a single norm-instead implying that there is a norm for individual people. Thus, rather than requiring us to define normality, this might introduce greater flexibility towards any people whose embodiment differs from the standard and consequently the possibility of a radical rethinking of what 'normality' might look like, which could have positive outcomes. ${ }^{117}$ Of course, with greater availability of restorative technologies, there may be implications for those who are unable to make use of these technologies, or who do not wish to do so. Individuals who 'acquire' disability later in life are likely to have stronger motivation to restore their ability. However, for many disabled individuals, if they were born with a disability or developed it at a young age, living with their current abilities is their normality. Society and employers have a legal obligation to accommodate disability. There may be no desire on the individual's part to alter this, but if the means exist by which they could, it may become difficult or even unacceptable in the view of society, for them to choose not to, and this could eventually have implications for the ongoing level of the support the state feels able to provide.

Issues that relate to equity and fairness may be exacerbated among disabled individuals. Lower employment rates within this group affect the means by which they are able to pay for an enhancement. Also, although there is a legal obligation on the state to provide some forms of support to disabled people, this will be challenged by interventions that are restorative but that are indistinguishable from enhancing ones. Examples such as methylphenidate (commonly known as Ritalin) are already relevant here because individuals clearly exist along a scale of abilities, and defining a single point beyond which someone is considered to suffer from ADHD is very difficult. Definitions in this realm are notoriously problematic. If we take sight as an example, when older people choose to correct a decline in visual perception, it is not clear whether this is restoration or enhancement, given that such decline is common among their peers. Decisions will need to be made whether to extend provision to all or restrict it to those considered disabled. In the latter case, subsequent decisions about how to define eligibility will be difficult and may counter any blurring of the boundary.

\section{Dr Scully expressed concern that the} development and use of enhancing technologies among disabled individuals could lead to a regression in how disability is viewed. Over the past two decades, there has been a shift from the so-called 'medical' or individual model of disability, where the 'problem' is something wrong with the person, to various forms of social-environmental models, in which physical or attitudinal barriers of society play a role. The social model has explicitly become part of UK disability policy. However, the availability of technologies that are perceived to 'fix' a disabled individual could impact on the positive change in attitudes, with a reversion to the 'individual problem' view of disability that places the responsibility to adapt with the disabled person (e.g. expecting them to provide the assistive technology so that they are competitive in the market place). The risk that technology may be seen as a means by which individuals can endure increasingly intolerable working conditions is again significant here. Many disabled people would be able to participate in work without restorative intervention if, for example, there was greater tolerance to their requiring shorter working days or working more slowly on some aspects of work. 


\section{Consequences for societal values}

There has been considerable debate around how enhancement would impact on individuality and identity, for example around whether there are risks to one's sense of identity and perception of 'self' when making use of an enhancement, and particularly if individuals start to make use of multiple enhancements. ${ }^{118,119}$ This may have some particular manifestations in the context of work. For example, there may be implications for our feeling able to take credit for our achievements or for others acknowledging the success of individuals, which might be accompanied by effects on societal appreciation for virtues such as motivation and hard work.
Enhancement may also produce shifts in the perception of various occupations. If an occupation requires a skill that can be acquired through the use of enhancement technologies, it may lose status compared with those perceived to require skills that are less open to acquisition. Public engagement commissioned by the Academy of Medical Sciences in 2007, to explore views on the use of cognitive enhancers, revealed that the effort and motivation involved in learning are seen as having intrinsic value. There was a perception that this value would be reduced with the use of cognitive enhancers, consequently devaluing 'normal' human achievements. 120

118 Farah, M. et al. (2004). Neurocognitive enhancement: what can we do and what should we do? Nature Reviews Neuroscience 5, 421-425. 119 Morein-Zamir S \& Sahakian BJ (2011). Pharmaceutical cognitive enhancement. In Illes ] \& Sahakian B] (eds) (2011). Oxford handbook of neuroethics. Oxford University Press, Oxford, UK.

120 Academy of Medical Sciences (2007). drugsfutures: public engagement on the future of brain science, addiction and drugs. Academy of Medical Sciences. London. 


\section{Policy and regulatory implications}

\section{Overview}

The use of enhancement at work raises several policy issues and potential regulatory challenges, such as whether enhancements should be mandatory, encouraged, permitted or prohibited, and whether this varies in different circumstances. The context of work may be unique because employees are in a vulnerable position and because work is inherently competitive. A degree of flexibility will be required in the selection of appropriate regulatory approaches and ongoing monitoring will be essential.

\section{What are the general policy implications?}

The use of enhancement technologies in the context of work raises a diverse and potentially widespread range of questions. Although some aspects of technological development, such as memory capacity, are fairly predictable, this is not the case for all fields. In addition, we cannot foresee all of the technologies that will be used and applied to work. Further, not only will the field of human enhancement evolve, but so will the world of work. The concept of work as a collective activity in which individuals effectively sell their services to an employer is relatively new compared with the idea of enhancing one's abilities. We are now seeing further transformation in terms of, for example, harnessing collective intelligence, and in 50 years' time work is likely to look very different to its current form. We must develop a better understanding of work and how it is performed if we are to identify potential impacts of enhancement technologies sufficiently. Not only this, but we must appreciate the particular instances where employees' and employers' interests diverge, particularly where there are implications beyond work, for example on personal life.

Reflecting on the possible uses of enhancement technologies, Professor Jonathan Montgomery, Professor in Health Care Law at the University of Southampton and incoming Chair of the
Nuffield Council on Bioethics, summarised three broad policy drivers that might influence the use of enhancement technologies:

- Reducing the impact of demographic changes and disability on individuals' lives. Enhancement may help us overcome these challenges, but debate will be needed to determine to what degree it should be part of the solution.

- Equality of opportunity and improved productivity. Many of the technologies identified at the workshop could address issues of opportunity and enable improved productivity. Again, enhancement cannot replace endeavours such as education and we must carefully consider the extent to which enhancement should form part of the solution.

- Infrastructure around innovation. Enhancement technologies will encounter significant pre-existing challenges to innovation, such as the regulation of medical devices and the slow rate of adoption of new technologies in healthcare.

This evolving field brings numerous challenges with which policy-makers must contend. Not only this, but as Professor Brian Collins FREng, Professor of Engineering Policy at University College London and former Chief Scientific Adviser to the Departments for Transport and Business, Innovation and Skills, highlighted, policy decisions are based on multiple considerations; although science and engineering are important, decisions are 
complex and driven by, for example, personal perspectives and experiences. Ongoing dialogue between policy-makers and individuals from across disciplines is therefore critical to efforts to monitor what the future of work might look like and to progress policy appropriately. This is necessary at both a national and international level.

Policy issues concerning enhancement technologies relate to claims that public policy and resource decisions are required. As always, a key question is around whether emerging enhancement technologies raise any new policy questions, compared with past examples of novel technologies. Professor Montgomery believes that many of the potential dilemmas have been addressed in previous contexts. For example, parallel questions relating to accessibility and claims for public funds were previously raised in relation to in vitro fertilisation (IVF) and issues around surveillance that might relate to life-logging have been discussed in relation to the growing use of closed-circuit television.

A particular challenge of many of the technologies lies in the fact that cost-benefit assessments will apply across different government departments. For example, the benefits of restorative technologies are likely to be of interest to the Department of Health, both health and social care, but also to, for example, the Department for Work and Pensions. Participants noted that some enhancements can be considered 'spend-tosave' technologies where benefits will be seen across government departments; decisionmaking processes must reflect this.

Participants highlighted the difficulties in gathering data to inform policy on human enhancement. Studies on the use of cognitive enhancers in healthy individuals face challenges in passing ethical approval, data to support the use of new devices is not required for marketing approval as it is for drugs, and the use of enhancers often occurs in an unregulated atmosphere, such as through online drug purchases.

\section{How might enhancement be regulated at work?}

When considering the policy, and particularly regulatory, implications of human enhancement, it is important to consider both public and private policy and to recognise that these interact. Regulation needs to reflect societal values, but with the fast pace of technological progress it can often lag behind developments, particularly in the case of new devices, which are subject to less regulation than drugs. Given the increasing market for devices, including in the field of enhancement, it is critical that we consider carefully what the most appropriate regulatory structure might be. We must also consider whether the context of work is different to any other, for example elite sport or the military.

Broadly speaking, three approaches might be taken to regulating the use of enhancement technologies in the workplace: top-down regulation, i.e. governmental; bottom-up, i.e. self-regulation where rules are determined by individual employers (possibly in consultation with employees); or a hybrid approach of co-regulation where a top-down element embeds the public interest but then leaves other aspects for self-regulatory decision. ${ }^{121}$

To decide between these approaches, Professor Roger Brownsword, Professor of Law at King's College London, considered where the potential problems lie with self-regulation. The options available to employers within this system are broadly as follows: to require enhancement; to allow individual employees to choose; or to prohibit enhancement. People may object to a system where employees cannot choose how to 
behave on the grounds that this compromises human dignity. However, such an objection could be made to either a top-down or a bottom-up system.

A second objection might be that enhancements can cause harm, both to users and non-users. For individual users, harms may be caused by using a technology. No technology is zero risk and individuals must therefore judge acceptable risk. This judgment of risk will vary with different circumstances; employees may draw very different conclusions about risk-benefit ratios from each other and from their employer, which could cause difficulties in a system of self regulation. Of course, a system of topdown regulation does not guarantee confidence because regulators will not always be able to spot potential harms.

Some commentators have pointed out that individuals who wish to enhance often do so primarily out of an intrinsic desire to enhance; any motivation to derive a positional advantage is secondary. ${ }^{122}$ However, Professor Brownsword noted that the nature of work means that any decision to enhance, whether by the employer or the employee, is made in an inherently competitive context; the competitive advantage gained is inescapable. Thus, work might be considered to be a unique or, at the least exceptional, context.

This view gains further strength when we consider that employees are in a vulnerable position. As discussed in Chapter 5, there is a risk that enhancement technologies could be used as a substitute for improved working conditions to offset a very challenging working environment. Even if enhancement is not formally required, in particularly target-driven situations that look to maximise productivity, if an employer's expectations are based on the performance of those using enhancers, then employee choice could be compromised.

And if we extrapolate further, is it possible that those not using enhancers might eventually be considered 'disabled' in some way? There is an established view that a labour contract is different from other types of contract because of the relations of power and authority embedded in it. ${ }^{123}$ In addition, most employees are unlikely to be in a position where they can select a job and employer based on their rules about enhancement. It is likely that any such rules need to be accepted along with any other terms of employment.

Thus, in many ways, work represents a unique context, within which a cautionary regulatory approach is desirable, with the primary objective of protecting employees. Selfregulation is not in the interests of employees and regulators might therefore need to consider a top-down approach.

The regulation of enhancement is complex, as can be illustrated in relation to the use of enhancements by long-distance lorry drivers. There might appear to be a relatively simple regulatory solution to driver tiredness in which government regulation stipulates maximum hours for which lorry drivers can work. However:

- If employees in other countries can drive for longer with the use of enhancements, the organisations in which enhancements are not used could be at a competitive disadvantage. The potential implications for national economies in such a situation could be significant. It is entirely possible that regulatory boundaries will be pushed to enable enhanced people to work for longer. 
- There may be an argument in favour of lorry drivers using enhancements to avoid tiredness and minimise danger to themselves and others, which some might consider to be almost for altruistic purposes.

The resolution of such dilemmas would require extensive discussions relating to the rights of employers, employees, wider society and stakeholders such as trade unions.

Participants stressed that regulation will also need to acknowledge that enhancement technologies are likely to be used for both restoration and to take individuals 'beyond the norm'. The issues are likely to be different for each. For example, where an enhancement has uncertainties or risks, these are more likely to be accepted by the user if they are attempting to correct a disability. Thus, if restorative applications might be able to diminish the boundary between the disabled and the nondisabled, regulation would ideally promote this outcome, as well as protect employees. In this case, it must address two agendas. Of course, efforts to define any boundary will counteract any blurring of that boundary. Flexibility in any regulatory approach will be important in a new area such as this. 


\section{Conclusion}

Advances in a range of areas in science and engineering such as neuroscience, regenerative medicine and bionics are already enhancing, or could in the next decade enhance, the physical and cognitive capacity of individuals in the workplace. The motivation for the development of many of the human enhancements discussed at the workshop has been to restore lost or absent cognitive or physical functionsrelevant both to increasing access to work for the disabled and delaying degeneration that could support an ageing workforce. However, there are clearly also applications for healthy individuals, to take them beyond the general 'norm'. Whether enhancements can reach the market, within or outside of the health sphere, will depend on their estimated market potential. This will be influenced by the regulatory framework, the time taken to market and the efficacy and acceptability of the technologies for users, employers and wider society.

Human enhancement has been discussed extensively in the academic literature, as have the various implications (e.g. for equity and fairness) of new and emerging technologies that may deliver enhancements. However, a body of research is lacking both on the implications of these technologies in the workplace, and, in many cases, the longterm health impacts of many of them. This workshop brought together a multi-disciplinary group of speakers and participants to explore this new topic and initiate the debate on the implications of human enhancement in the workplace with the aim of identifying areas requiring further scrutiny.

The power imbalance in the employeremployee relationship, particularly during difficult economic times (when employees are unlikely to be able to pick and choose jobs based on enhancement polices) was regarded as raising some unique issues for the debate about human enhancements, for example relating to actual or perceived coercion.
Participants highlighted a significant tension between the potential for enhancements to 'humanise' the workplace (improving the work environment for more effective working for shorter periods) or to substitute for healthy working conditions (e.g. encouraging the use of modafinil to offset the impacts of jetlag rather than encouraging video conferencing to replace long-haul flights). A particular example of this pertained to the use of human enhancement technologies to facilitate access to work for disabled people. As one speaker made clear, the availability of these technologies might risk undermining the rights of disabled people to have workplaces designed to accommodate them, and instead place on them the expectation to accommodate to the workplace by using enhancement technologies.

Assessing the potential social, ethical and regulatory implications of these technologies is complex because of both the variety of contexts in which the enhancement technologies could be used, and the range of likely impacts on the user and others. This complexity is highlighted by a sample of the questions identified by participants that might need to be addressed in any given situation:

- Does an individual have, or perceive they have, free choice in terms of using the enhancement?

- Who is paying, or who can afford to pay?

- Does the decision to enhance or not have an impact on the wellbeing of others (e.g. by increasing or decreasing their safety)?

- Does the enhancement significantly increase the competitiveness of the individual, the employer or the national economy?

A key question is who should decide how enhancements should be controlled and regulated, for example government, employers or individuals? At the workshop it was proposed that some element of 'top-down' regulation of enhancements in the workplace would be required to protect the public interest. However, 
it was clear that there would be pressure to permit, encourage or even obligate the use of enhancements if they could be shown to increase the safety of others, for example in the context of medical practitioners or transport workers. Likewise, there will be calls for enhancements to be permitted to provide a level playing field for UK businesses if other countries are using enhancements. Both these contexts may lead to the coercion of employees to take up enhancements.

As previously highlighted, this workshop represented the very start of the debate on the implications of human enhancement in the workplace. It is hoped that this report will stimulate further debate and research, particularly to address the 'known unknowns' identified by participants. Gaps in our knowledge could be addressed by:

- Studies on the long-term impacts of the enhancements on the individual both in terms of efficacy and harm (e.g. of cognition enhancers on the developing brain of young adults). This information is essential in providing a rigorous cost-benefit analysis for individuals, policy-makers and wider society. Here the lower level of scrutiny of devices (compared with drugs) and the difficulty of collecting data where enhancements are used outside the medical setting (e.g. not prescribed) present particular challenges.

- Rigorous consideration of the complex ethical and social impacts of human enhancement in the workplace.

- Deliberative dialogue with users, potential users and the wider public that is crucial to guide the development of these technologies and inform the development of regulation and guidance.

- The development of a market map of enhancement technologies that includes time to market, regulatory considerations, cost of development, the target of the technology and the global context.

It was clear from the discussions that cognition-enhancing drugs present the greatest immediate challenge for regulators and other policy-makers. They are already available without prescription through internet purchasing, are relatively cheap and are increasingly being used by healthy individuals. These might therefore be a high priority for continued attention. In addition, digital services and devices with very significant cognitive enhancing effects are emerging continuously. They often attract little regulatory oversight and consequently impact analyses are rarely undertaken. Studies and commissioned research are required to assess rigorously the risks and benefits that will arise from such services and devices.

Ensuring that the potential benefits of human enhancement technologies in the workplace are realised while the risks are minimised will draw on the combined expertise of the disciplines represented by the four academies, and require dialogue with potential users and the wider stakeholder community. The approaches taken will need to evolve in response to changes in the underpinning science and technology as well as changes in the nature of work. 


\section{Annex I Workshop programme}

\section{Welcome and introduction}

Professor Genevra Richardson CBE FBA, Steering committee Chair

\section{Developments in science and engineering \\ Chair: Dr Robin Lovell-Badge FRS FMedSci}

\section{Cognitive enhancement}

Pharmacological cognitive enhancement -

Professor Barbara J Sahakian FMedSci, Professor of Clinical Neuropsychology,

University of Cambridge

Non-pharmacological cognitive enhancement -

Professor Nigel Shadbolt FREng, Professor of Artificial Intelligence, University of Southampton

Cognitive training and gaming -

Dr Paul Howard Jones, Senior Lecturer in Education, University of Bristol

\section{Respondents}

Cognitive maintenance -

Professor John O'Brien, Professor of Old Age Psychiatry, Newcastle University

Non-invasive brain stimulation -

Dr Roi Cohen Kadosh, Wellcome Research Career Development Fellow, University of Oxford

\section{Physical enhancement}

Physiology and tissue engineering -

Professor Molly Stevens, Professor of Biomedical Materials and Regenerative Medicine,

Imperial College London

Sensory enhancements - Human Hearing -

Professor Brian Moore FRS FMedSci, Professor of Auditory Perception, University of Cambridge

Sensory enhancements - Human vision -

Dr Matteo Rizzi, Postdoctoral Fellow, University College London

Prosthetics and exoskeletons -

Dr Laurence Kenney, Reader in Rehabilitation Technologies, University of Salford

\section{Respondents}

Internal organ enhancement -

Professor Stephen Westaby, Cardiac surgeon, John Radcliffe Hospital, Oxford

Nutrition and performance enhancement -

Professor Ron Maughan, Professor of Sport and Exercise Nutrition, Loughborough University 


\section{Opportunities and challenges \\ Chair: Professor Janet Radcliffe-Richards}

\section{Commercial opportunities and challenges}

Open discussion led by a panel of experts:

- Mr Phil Newman, CEO, PERGALI

- Dr Andrew Elder, Partner, Albion Ventures

- Mr Paul Mason, Head of Development, Technology Strategy Board

- Professor Nikolas Rose, Professor of Sociology and Head, Department of Social Science, Health \& Medicine, King's College London

\section{Implications for the future of work}

Open discussion led by 10 minute reflections from speakers addressing the following topics:

Social and ethical implications -

Dr Ilina Singh, Reader in Bioethics and Society, London School of Economics and Political Science

Disability and normality -

Dr Jackie Leach Scully, Reader in Social Ethics and Bioethics and Co-Director,

Policy Ethics and Life Sciences Research Centre, Newcastle University

Psychosocial perspective -

Dr Pamela Gallagher, Senior Lecturer in Psychology, Dublin City University, Ireland

Principles of regulation -

Professor Roger Brownsword, Professor of Law, King's College London

\section{Policy priorities, conclusions and closing remarks Chair: Professor Genevra Richardson CBE FBA}

Professor Brian Collins FREng,

Professor of Engineering Policy, UCL and former Chief Scientific Adviser, Department for Business, Innovation and Skills and Department for Transport

Professor Jonathan Montgomery,

Professor in Health Care Law, University of Southampton and incoming Chair, Nuffield Council on Bioethics 


\section{Annex II Steering committee membership}

\section{Professor Genevra Richardson CBE FBA (Chair)}

Professor of Law, King's College London

\section{Professor Paul Edwards FBA}

Professor of Employment Relations, Birmingham Business School

\section{Dr Robin Lovell-Badge FRS FMedSci}

Head of Division of Stem Cell Biology and Developmental Genetics, MRC National Institute for Medical Research

\section{Mr Phil Newman}

Chief Executive Officer, PERGALI

\section{Professor Barbara Sahakian FMedSci}

Professor of Clinical Neuropsychology, University of Cambridge

\section{Professor Nigel Shadbolt FREng}

Professor of Artificial Intelligence, University of Southampton

\section{Professor Jonathan Wolff}

Professor of Philosophy, University College London

\section{Secretariat}

The project secretariat was drawn from across the four academies:

Ms Catherine Luckin Academy of Medical Sciences (lead secretariat until April 2012)

Dr Richard Malham Academy of Medical Sciences (from May 2012)

Dr Rachel Quinn Academy of Medical Sciences (lead secretariat)

Ms Helen Haggart British Academy

Ms Katherine MacGregor Royal Academy of Engineering

Ms Sarah Mee Royal Society 


\section{Annex III Workshop participants}

Professor Robin Ali FMedSci

Professor of Human Molecular Genetics

University College London

Professor Frans Brom

Head, Technology Assessment and Professor

in Ethics of Technology Assessment

Rathenau Institute and Utrecht University

Professor Roger Brownsword

Professor of Law

King's College London

Professor Cary Cooper

Distinguished Professor of Organizational

Psychology and Health

Lancaster University Management School

Ms Helen Clements

Health and well-being Directorate,

Health and work strategy

Department of Work and Pensions

Dr Roi Cohen Kadosh

Wellcome Research Career

Development Fellow

University of Oxford

Professor Brian Collins FREng

Professor of Engineering Policy

University College London

Dr Claire Craig

Deputy Head

Government Office for Science

Professor Paul Edwards FBA

Professor of Employment Relations

University of Birmingham

Dr Andrew Elder

Partner

Albion Ventures

Mr Fazal Fatah

President

British Association of Aesthetic

Plastic Surgeons

Dr Pamela Gallagher

Senior Lecturer in Psychology

Dublin City University

Mr James Gallagher

Health and Science Reporter

BBC News

Mr Oliver Grant

Foresight Horizon Scanning Centre

Mr Mike Gray

Ergonomist

Health and Safety Executive
Professor John Harris FMedSci

Sir David Alliance Professor of Bioethics

\& Director of iSEI

University of Manchester

Professor Mark Hawley

Professor of Health Services Research

University of Sheffield

Mr Graeme Henderson

Head of Health and Work

Department of Health

Dr Paul Howard Jones

Senior Lecturer in Education

University of Bristol

Professor Les Iversen FRS

Chair

Advisory Council on the Misuse of Drugs

Dr Laurence Kenney

Reader in Rehabilitation Technologies

University of Salford

Professor Tom Kirkwood FMedSci

Director, Institute for Ageing and Health

Newcastle University

Dr Jackie Leach Scully

Co-Director, Policy, Ethics \& Life Sciences

Research Centre

Newcastle University

Dr Robin Lovell-Badge FRS FMedSci

Head of Division of Stem Cell Biology and

Developmental Genetics

MRC National Institute of Medical Research

Mr Paul Mason

Head of Development

Technology Strategy Board

Professor Ron Maughan

Professor of Sport and Exercise Nutrition

Loughborough University

Professor Brian Moore FRS FMedSci

Professor of Auditory Perception

University of Cambridge

Professor Jonathan Montgomery

Professor in Health Care Law and

incoming Chair

University of Southampton and Nuffield Council on Bioethics

Professor Richard Morris FRS FRSE FMedSci

Royal Society/Wolfson Professor of

Neuroscience

University of Edinburgh 
Mr Phil Newman

Chief Executive Officer

PERGALI

Professor John O'Brien

Professor of Old Age Psychiatry

Newcastle University

Dr Martyn Pickersgill

Wellcome Trust Senior Research Fellow in

Biomedical Ethics

University of Edinburgh

Professor Janet Radcliffe-Richards

Professor of Practical Philosophy

University of Oxford

Lt Col Simon Redman

Medical Futures and Concepts

Ministry of Defence

Professor Genevra Richardson CBE FBA

Professor of Law and Steering Committee Chair

King's College London

Dr Matteo Rizzi

Postdoctoral Fellow

University College London

Professor Nikolas Rose

Professor of Sociology and Head, Department of

Social Science, Health \& Medicine

King's College London

Professor Barbara Sahakian FMedSci

Professor of Clinical Neuropsychology

University of Cambridge

Alex Salvoni

Head

Foresight Horizon Scanning Centre

Dr Anders Sandberg

James Martin Research Fellow

Future of Humanity Institute, Oxford University
Professor Nigel Shadbolt FREng

Professor of Artificial Intelligence

University of Southampton

Professor Noel Sharkey

Professor of Artificial Intelligence and Robotics

University of Sheffield

Dr Ilina Singh

Reader in Bioethics and Society

London School of Economics and Political

Science

Professor Molly Stevens

Professor of Biomedical Materials and

Regenerative Medicine

Imperial College London

Professor Lorraine Tyler FBA

Professor of Cognitive Neuroscience

University of Cambridge

Professor Julian Vincent

Honorary Professor of Biomimetics and

Scientific Advisor

University of Bath and Swedish

Biomimetics 3000

Dr Alan Wallace

Investment Director

Octopus Ventures

Professor Jeremy Watson FREng

Chief Scientific Adviser

Department for Communities and

Local Government

Professor Stephen Westaby

Cardiac surgeon

University of Oxford

Professor Jonathan Wolff

Professor of Philosophy

University College London 
Aberrant learning: Dysfunctional or maladaptive learning, whereby false or spurious associations are made. This can be due to the action of drugs.

Attention-deficit-hyperactivity disorder (ADHD): A neuropsychiatric disorder encompassing a range of behavioural symptoms, including hyperactivity and inattentiveness.

Affective response: An instinctive emotional response to a stimulus or situation.

Age-related macular degeneration (AMD): A condition that affects a part of the retina called the macula, and a major cause of visual impairment in older adults. It is the most common cause of retinal degradation in industrialised countries.

Ambient computing: The introduction of computational capacity into a wide range of objects that share information; for example, a refrigerator with a display that notifies a person of when food or medications will expire.

Amyloid cascade: A hypothesised mechanism whereby a crucial step in Alzheimer's disease is the deposition of a particular substance (amyloid- $\beta$ peptide) in brain tissue.

Anabolic: Pertaining to metabolic pathways in the body wherein more complicated molecules are constructed from simpler precursors. These metabolic pathways also result in generation of new tissue, such as muscle, which is associated with the abuse of anabolic steroids.

Androgenic: Relating to the development of masculine traits, for example body hair and muscle mass.

Asymptomatic: A lack of noticeable symptoms. This may mean that the individual concerned is a carrier for a disease, or a disease is in a 'dormant' phase.

Atomoxetine: A drug approved for treatment of attention-deficit-hyperactivity disorder, which inhibits the reuptake of noradrenaline (a neurotransmitter).

Attentional biases: A set of perceptual distortions wherein attention is disproportionately drawn by certain stimuli in an environment, resulting in the neglect of additional relevant stimuli when making judgements.

Augmented intelligence: The achievement of increased intelligence, typically through the use of information technology.

Augmented reality: Interaction with the physical world that is supplemented with computergenerated sensory input, for example GPS data or sound.

Bioactive: Materials that interact with or affect (human) cells or tissues. 
Biofeedback: The process of feeding back to an individual information regarding their physiological activity, for example brainwave or muscle contraction data, acquired using precise instrumentation. Biofeedback is being increasingly used in prosthesis control.

Biological trade-offs: A biological trade-off occurs when increasing adaptation and optimisation of one aspect of an organism's function necessitates the worsening of another.

Bionic limbs and exoskeletons: Mechanical or electrical devices that supplement naturally occurring human body parts.

Bottom-up regulation: See Self-regulation.

Brain stimulation, deep brain stimulation: Brain stimulation involves touching or activating specific parts of the brain with electricity, magnets or implants. Deep brain stimulation involves the implantation of electrodes in the brain that, like a pacemaker, are powered and controlled by a generator implanted in the chest.

Brain-computer interfaces: A direct link between a brain and an external device, which enables communication and control without user movement by inferring intent from direct measurements of brain activity.

Cholinesterase inhibitors: Drugs that inhibit the reuptake of acetylcholine (a neurotransmitter) by neurons. Their use can be effective in managing the symptoms of Alzheimer's in early stages or moderate cases of the disease.

Cochlea, cochlear implants: The cochlea is the part of the inner ear that converts vibrations (usually from sound waves in the air, via the eardrum and middle ear bones) into nerve impulses. Cochlear implants are devices for the profoundly deaf or severely hard of hearing that provide useful representations of sounds. The implant consists of an external portion with microphone(s) that sits behind the ear and a second portion that is surgically placed under the skin, which filters and converts the signals into electric impulses, sending them to electrodes wound through the cochlea allowing them to be transmitted directly to the brain via the auditory nerves.

Cognition: flexibility, impairment, maintenance, training: Cognition describes a set of mental processes including memory, problem solving, decision making and attentiveness.

Cognition enhancing drugs: Drugs that modulate cognition.

Collective cognition: Cognition performed by a group of individuals through their communication and collaboration.

Compute complexity: The compute complexity of an analysis describes the computing resources required to perform the analysis.

Computing fabric: Interconnected computer processors and data storage that are used to perform computational tasks. 
Contrast sensitivity: A measure of the ability to see detail at low contrast, i.e. the ability to see the difference between components in the visual field when there is little variation in their brightness.

Crowd-sourcing: Performing a task or collecting data through the efforts of multiple volunteers. This is increasingly used in online information sharing, for example Wikipedia.

Decision support systems: Computer programs and data used to assist analysis and decisionmaking.

Deliberative dialogue: A process for seeking shared understanding of a problem and identifying common ground for action, including potential compromises, within a diverse group. The process is led by a trained facilitator.

Dementia: A group of symptoms describing pronounced (i.e. beyond the common effects of aging) decline in the brain and its functions. There are two broad forms: static dementia and progressive dementia, with the latter worsening over time.

Developmental dyscalculia: A learning disability specifically affecting arithmetic capability that is present from childhood. It is thought to be a brain disorder with inheritable genetic causation, although environmental factors such as teaching and deprivation have also been implicated.

Dopamine receptor, dopaminergic reward system: Dopamine is a natural neurochemical responsible for reward-driven learning. Some highly addictive drugs act on dopamine systems in the brain.

EarLens system: A hearing system wherein sound is picked up by a microphone in or near the ear canal, and audio signals and power are transmitted by a laser to a receiver resulting in a transducer vibrating the eardrum directly.

Endogenous glycogen stores: Reserves of carbohydrates (sugars) produced from excess ingested sugars and stored inside the cells of liver and muscle tissue. They are created or used to maintain levels of blood glucose.

Episodic memory: The memory for the what, where and when of specific events or experiences. An example is remembering where you have parked your car. The hippocampal formation, a region of the brain affected early in Alzheimer's disease, plays a critical role in episodic memory.

Executive functions: Cognitive processes involved in the conscious and directed planning and execution of daily activities, for example problem solving and multi-tasking.

Functional Magnetic Resonance Imaging (fMRI): A technique which detects changes in blood flow to specific areas of the brain, which are used to infer changes in neural activity in those areas.

Foot drop: A condition wherein nerve damage or muscle paralysis leads to an inability to raise the forefoot. 
Foveola: A point in the retina of the eye that contains densely packed photoreceptors, therefore potentially the part of the retina responsible for the highest visual resolution.

Gene supplementation: The insertion of corrective genes into the genome of an individual with a genetic disease. Also referred to asgene therapy.

Gene transfer: The insertion of new segments of DNA into a host cell's genome.

Germ-line gene modification: Making inheritable genetic changes, achieved by engineering either the cells responsible for offspring (germ-line cells) or very early stage embryos.

Goal theory: A theory which states that setting goals and achieving them is the main driver of human motivation.

Global Positioning System (GPS): A satellite-based navigational system. GPS receivers are a common feature of modern mobile electronic devices.

Growth factor: A naturally occurring substance that can stimulate aspects of a cell's behaviour such as to grow and proliferate.

Human enhancement: This term encompasses the use of a range of approaches or endeavours to modify aspects of human function. The joint academies' workshop was concerned with both restoring an impaired function to previous or average levels, or raising a function to a level considered to be 'beyond the norm' for humans. This report considers all forms of enhancement that directly alter the individual, but excludes alterations to the wider environment that enhance human interactions with it. It is important to note that there is no consensus on how and whether humans might be 'improved', or that only positive outcomes will arise.

Immersive technology: Technology that creates a sense of immersion by blurring the line between the physical and virtual world. These technologies typically require the incorporation of multiple components, for example gesture-based control systems and 3D displays.

Inherited retinal degeneration: Inherited retinal degeneration is commonly attributed to changes in genetic sequence or gene regulation, often for the gene encoding the light-sensitive protein rhodopsin.

Intellectual property: Property that results from creations of the mind. Legal rights to this property may be asserted through patents, copyright or trademarks.

Intragastric infusion: Supply of a liquid directly into the stomach using a tube, for example 'tube feeding'.

'in vivo' bioreactor: Using the body's healing mechanisms to engineer new tissue. In the case of bone, this was achieved by the careful engineering of an artificial space between tissues. More generally, this term can refer to the production of any cells or proteins in an animal.

Jetlag: A sleep disorder resulting from fast long distance travel between time zones. Also known as desynchronosis. 
Life logging: The continuous capture of data pertaining to one's life. This can now be more practicably achieved using computational means, for example portable cameras and/or wireless devices.

Market map: An analysis of a market segment that aids the positioning of a product relative to its competitors. This is usually based on two dimensions of consumer perception, for example quality versus price.

Memory: Memory refers to the processes that encode, store and retrieve information. See also, memory capacity, memory encoding, episodic memory and working memory.

Memory capacity: The amount of information that can be handled by memory.

Memory encoding: The receiving, processing and combining of information, for example visual stimulus, resulting in the generation of a memory.

Mental capital: A term describing an individual's cognitive and emotional resources, including capacity for learning and social skills.

Methylphenidate: A stimulant drug that inhibits the reuptake of dopamine and noradrenaline (both neurotransmitters) into neurons. More commonly known by the trade name Ritalin.

Mixed reality: An environment that merges the real with virtual worlds, such that physical and digital objects interact in real time.

Modafinil: Modafinil is a central nervous system wake promoting agent used for the treatment of excessive daytime sleepiness. It is commonly known by the trade name Provigil, and is used in the treatment of narcolepsy. Modafinil has effects on many neurotransmitters in the brain. Its cognitive enhancing effects are thought to be mediated primarily by noradrenaline and dopamine.

Motivation theories: Multiple theories have been developed in attempts to rationalise the mechanisms of human motivation. These are variously based on principles such as minimising pain, avoiding death or attaining a particular object or outcome.

Multi-channel compression: An operation that brings the frequencies and volumes of sounds audible to an unimpaired ear into the range audible by the user of a hearing aid. Multi-channel techniques are considered to result in better outcomes than single channel techniques.

Myocardium: The muscular middle layer of the heart wall, contraction of which generates the heartbeat.

Neurochemical: A substance that affects the nervous system.

Neurodegeneration: The progressive loss of neuronal structure or function, which can result in neurodegenerative diseases such as Parkinson's and Alzheimer's.

Neuronal excitability: The ability of a neuron to generate and propagate nerve impulses (action potentials). 
Neuropsychiatry: A medical discipline concerned with only those mental disorders that can be strongly associated with neurological conditions, such as head injuries.

Noradrenaline: A hormone and neurotransmitter released naturally by nerve cells, effecting 'fight or flight' responses such as increased heart rate.

Nutritional supplements: A mixture of nutrients, such as vitamins or amino acids, used to supplement components that may not be sufficiently consumed in an individual's diet. They are differentially defined as foods, drugs or health products in different nations.

PageRank: An algorithm used by the Google search engine to analyse interlinked web pages with the purpose of determining their relative importance.

Pervasive computing: An environment wherein almost all objects in the physical world have computational capacity and are interconnected.

Pharmacogenomics: The study of the influence of an individual's genetic variation on their response to pharmaceuticals.

Photoreceptors: Specialised neurons found in the retina that convert light input into nerve signals. There are two main types, rods and cones.

Placebo: Used in controlled clinical trials, the placebo is a 'dummy' treatment administered to the control group. This controls for the placebo effect, wherein simply the administration of a treatment can result in a psychosomatically-mediated improvement in conditions. A placebo therefore allows the specific and nonspecific effects of the experimental treatment to be distinguished.

Plasticity: The ability to adapt to changes in the environment.

Pluripotent cells: A type of stem cell capable of producing any foetal or adult cell type.

Prefrontal cortex, prefrontal cortical network: The brain region most implicated in performing executive functions, and closely linked to individual personality.

Prostheses: Artificial devices used as replacement body parts, such as a heart valve or limb.

Protein synthesis: An anabolic process wherein protein molecules are synthesised from amino acids.

Psychosocial: Pertaining to the effect of the social environment on the mind and subsequently the body. See Box 4 on page 36: 'The psychosocial perspective'.

Psychostimulation: The effects produced by stimulant drugs, i.e. the inducement of temporary changes in mental function.

Publics: The plural of public is used to recognise that the public is not homogeneous and contains sub-sections of society who have particular concerns e.g. patient or campaign groups. 
Real-time ultrasound: A form of ultrasound used to 'view' deep muscle contractions in real time.

Recombinant antibodies: Antibodies produced by genetically engineered microorganisms or animals (notably mice).

Regenerative medicine: A field of research and clinical practice concerned with repairing or replacing organs, tissues or cells.

Resilient neurodevelopment: Neurodevelopment that responds adaptively to stressful or traumatic circumstances or events.

Retinal implants: Implants designed to restore visual capacities such as object recognition or light perception to those who have suffered from degenerative eye conditions. This is achieved by the implant electrically stimulating retinal cells. Two types of implant are currently being clinically trialled, for placement both on and behind the retina.

Reverberant: An environment wherein sound persists (echoes), decaying slowly.

Self-regulation: In this context, a system where companies are responsible for regulating their own behaviour (e.g. through a code of practice) rather than being governed by legally binding regulations.

Self-regulatory theory: A system for managing personal health, wherein the self-regulation (desire to get better) of the patient is critical to the implementation of medical advice and resultant efficacy of the medical treatment.

Semantic Web: A movement, led by the World Wide Web Consortium, promoting the inclusion of metadata (semantic data) in web pages, to make it easier for users and programs to find and process data on the web.

Social computation: A branch of computer science that deals with the interface between computational systems and social behaviours: this can involve either the support of social behaviour through computational systems, or the use of social groups to carry out 'computations'.

Sociotechnical: Relating to the interaction between technological systems/technology and social systems/people.

Somatic gene therapy: The transfer of corrective genes into the somatic (i.e. any cells other than germ line) cells of a patient. This means that the corrective genes will not be passed on to the patient's offspring.

Stance phase: Part of the gait cycle, between the heel striking the ground and the toe lifting from the ground. 
Stem cells: embryonic: Stem cells differ from other cells in two ways: they are unspecialised yet renew themselves through cell division, and they can be induced to specialise under certain conditions. Embryonic stem cells can be derived from cells present in the very early embryo, before they have specialised into a specific tissue type. Research, originally in the mouse, demonstrated that these cells can give rise to all the cell types of the developing embryo and adult mouse; they are therefore considered 'pluripotent'.

Stimulant: See Psychostimulation.

Synaesthesia: A neurological condition in which stimulus in one sense leads to experiences in a second sense. For example, the month August visually evoking the colour brown.

Synapse: The structure which forms a junction between a nerve cell and another cell, which allows electrical or chemical signals to be transmitted between the cells.

Synthetic biology: A multidisciplinary branch of biological research and technological developments concerned with designing novel non-natural biological functions and systems.

Targeted muscle re-innervation: A technique for allowing amputees to control prosthetic limbs and regain sensory feedback. In muscles, multiple nerves are transferred into the target muscle, and the multiple signals from these nerves are used to control the prosthesis.

Tau protein: Proteins that normally stabilise sub-cellular structures called microtubules, but when defective result in dementias such as Alzheimer's.

Tissue engineering: The improvement or restoration of biological functions using the methods of engineering, biochemistry and medicine: most commonly the repair or replacement of whole tissues such as cartilage or bone.

Top-down regulation: A system wherein one entity (e.g. Government) is responsible for regulating the behaviour of multiple other entities (e.g. a particular sector of industry) often through legally binding regulations.

Trachea: Also known as the windpipe, this is the tube through which air flows from the larynx to the lungs.

Transcranial stimulation - magnetic, electrical: Transcranial stimulation is a method used to stimulate neurons in the brain. This can be achieved non-invasively with electromagnets positioned above the scalp (transcranial magnetic stimulation), or with electrodes placed onto the scalp (transcranial direct current stimulation).

Ventricular assist device: A pump used by those with weak hearts to support blood flow and heart functioning. 
Viral vectors: Viruses have evolved highly efficient mechanisms to introduce their genetic material into cells they infect. Viral vectors are engineered virus particles that exploit these mechanisms to introduce engineered genetic material into cells (while at the same time any disease-causing viral genes have been deleted).

Viscoelastic: Having both elastic (returns to original shape after stress) and viscous (resistance of a fluid to deformation by stress) properties.

Visual cortex: The part of the brain's cerebral cortex that processes visual information.

Visuomotor: Any movement that arises from or relies on sight.

Working memory: The system that actively holds information in the mind to do verbal and nonverbal tasks such as reasoning and comprehension, and to make it available for further information processing. 
The Academy of Medical Sciences

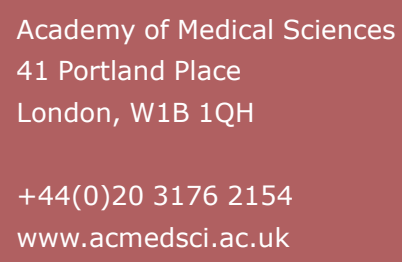

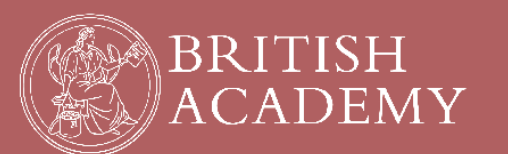

British Academy

10-11 Carlton House Terrace

London, SW1Y 5AH

+44(0)2079695200

www.britac.ac.uk
Royal Academy of Engineering 3 Carlton House Terrace London, SW1Y 5DG

$+44(0) 2077660600$

www.raeng.org.uk
THE

ROYAL

SOCIETY

The Royal Society 6-9 Carlton House Terrace London, SW1Y 5AG

$+44(0) 2074512500$ www.royalsociety.org 